Portland State University

PDXScholar

TREC Final Reports

Transportation Research and Education Center

(TREC)

7-2019

\title{
Characterizing the Trip Generation Profiles of Multifamily Housing
}

Kelly Clifton

Portland State University, kclifton@pdx.edu

Kristina M. Currans

University of Arizona

Follow this and additional works at: https://pdxscholar.library.pdx.edu/trec_reports

Part of the Transportation Commons, Urban Studies Commons, and the Urban Studies and Planning Commons

Let us know how access to this document benefits you.

\section{Recommended Citation}

Clifton, Kelly and Kristina Currans. Characterizing the Trip Generation Profiles of Multifamily Housing. NITC-RR-878. Portland, OR: Transportation Research and Education Center (TREC), 2019. https://doi.org/ $10.15760 /$ trec.231

This Report is brought to you for free and open access. It has been accepted for inclusion in TREC Final Reports by an authorized administrator of PDXScholar. Please contact us if we can make this document more accessible: pdxscholar@pdx.edu. 


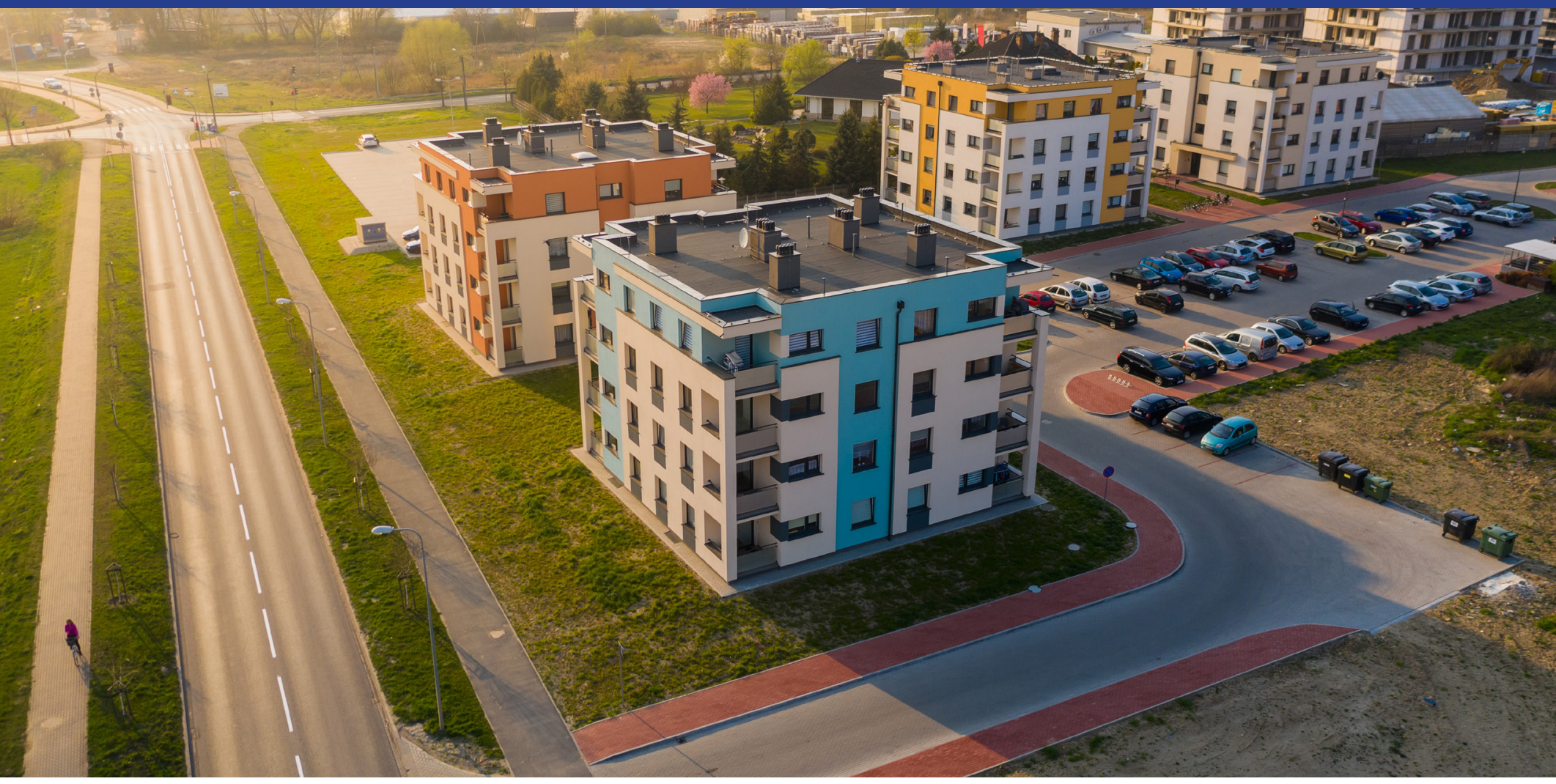

\section{Characterizing The Trip Generation Profiles Of Multifamily Housing}

Kelly Clifton, Ph.D.

Kristina Currans, Ph.D.

S Portland State

胥, OFE UNIIERSIIY 


\title{
CHARACTERIZING THE TRIP GENERATION PROFILES OF MULTIFAMILY HOUSING
}

\section{Final Report}

\section{NITC-RR-878}

\author{
by
}

Kelly J. Clifton (PI) ${ }^{1}$

Kristina M. Currans ${ }^{2}$

${ }^{1}$ Portland State University, ${ }^{2}$ University of Arizona

for

National Institute for Transportation and Communities (NITC)

P.O. Box 751

Portland, OR 97207
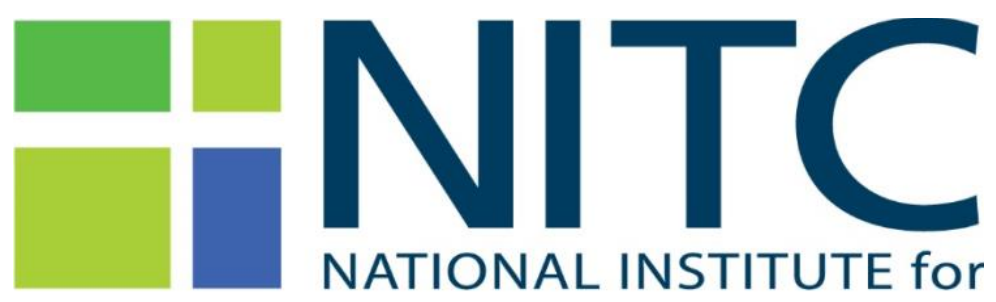

TRANSPORTATION and COMMUNITIES

July 2019 



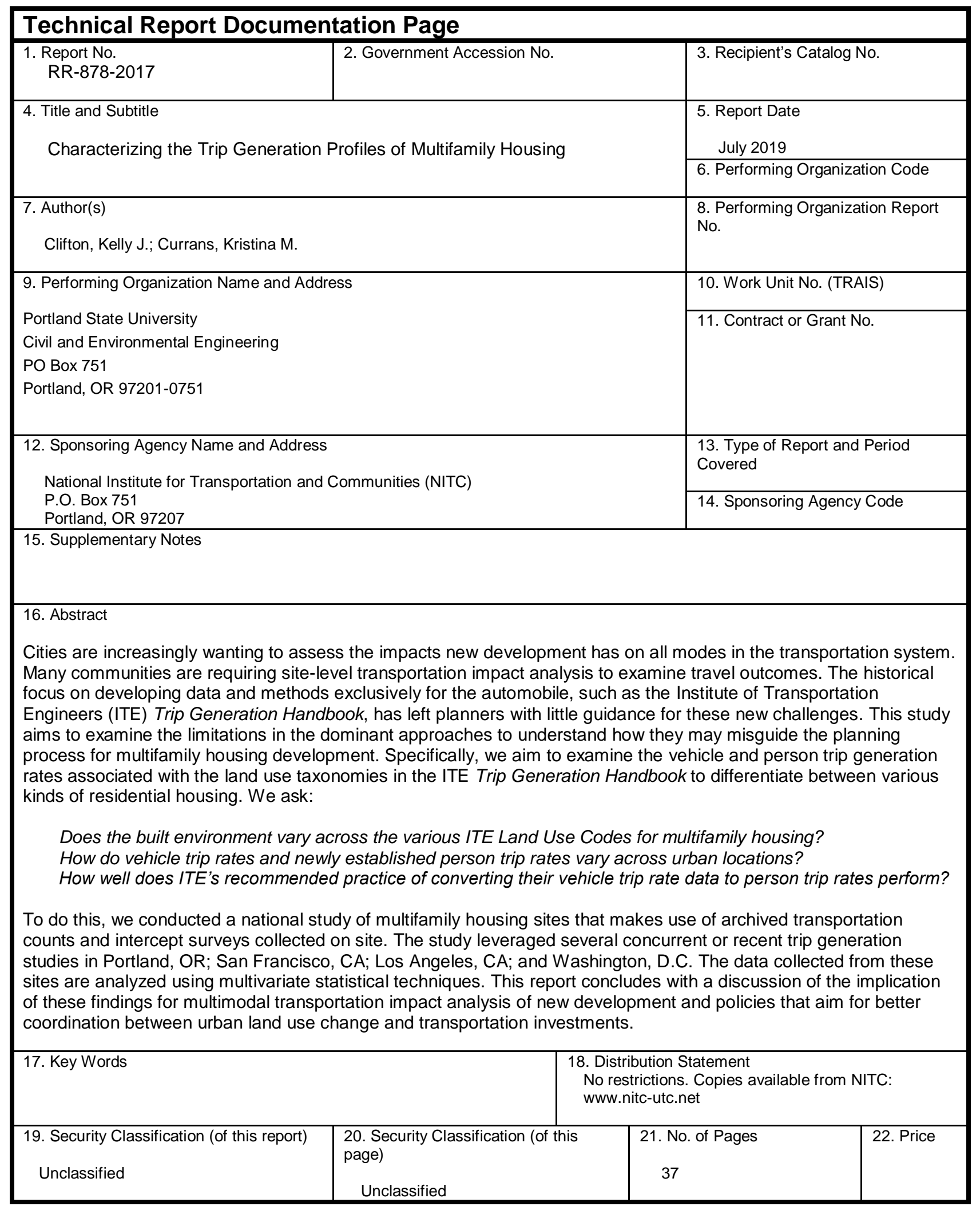




\section{ACKNOWLEDGEMENTS}

This project was funded by the National Institute of Transportation and Communities (NITC) under grant number 878 . Partial supplementary funding was provided by the Federal Highway Administration and Dwight David Eisenhower Graduate Transportation Fellowship, and the Portland State University Maseeh College of Engineering Graduate Fellowship.

\section{DISCLAIMER}

The contents of this report reflect the views of the authors, who are solely responsible for the facts and the accuracy of the material and information presented herein. This document is disseminated under the sponsorship of the U.S. Department of Transportation University Transportation Centers Program in the interest of information exchange. The U.S. Government assumes no liability for the contents or use thereof. The contents do not necessarily reflect the official views of the U.S. Government. This report does not constitute a standard, specification, or regulation.

\section{RECOMMENDED CITATION}

Clifton, Kelly and Kristina Currans. Characterizing the Trip Generation Profiles of Multifamily Housing. NITC-RR-878. Portland, OR: Transportation Research and Education Center (TREC), 2019. 


\section{TABLE OF CONTENTS}

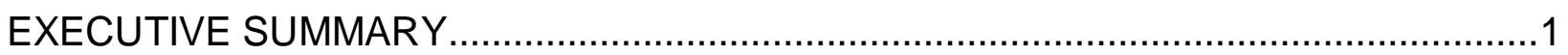

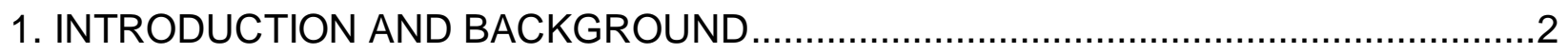

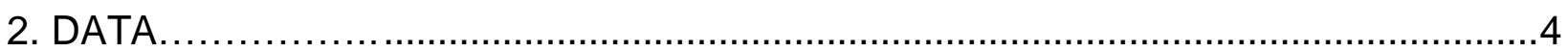

3. Q.1. DOES THE BUILT ENVIRONMENT VARY ACROSS THE VARIOUS ITE LAND USE CODES FOR MULTIFAMILY HOUSING? ...............................................

4. Q.2. HOW DO VEHICLE AND PERSON TRIP RATES FOR MULTIFAMILY HOUSING VARY ACROSS URBAN LOCATIONS?

Vehicle trip rates - Residential-only Sites ............................................... 17

Vehicle trip rates - Mixed-Use Sites........................................................... 20

Person trip rates - Residential-only Sites.................................................... 22

Person trip rates - Mixed-Use Sites ………………................................... 25

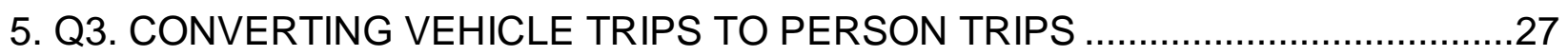

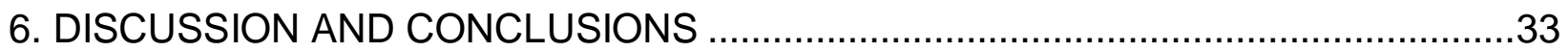

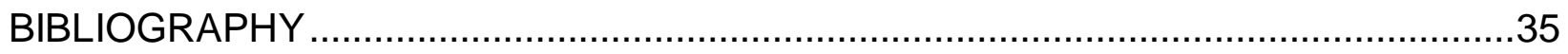




\section{LIST OF TABLES}

Table 1 Sources of Archived Trip Generation Data for Multifamily Housing Used in This Study 4

Table 2 Supplementary Built Environment Data Considered ....................................... 6

Table 3 Built Environment Descriptive Statistics ........................................................ 7

Table 4 Descriptive Statistics of Trip Generation and Transportation Impacts .................. 8

Table 5 ITE Descriptions of Land Use Codes (LUC) ................................................. 11

Table 6 ANOVA and Tukey Post-Hoc Tests of Variation in Built Environment Across ITE

Land Use Codes for Multifamily Residential ...................................................... 13

Table 7. Kruskal-Wallis Tests Results ( $p$-values) of the Variation of AM and PM Vehicle

Trip Rates Across Land Use Categories ........................................................... 18

Table 8 Negative Binomial Regression Results for Vehicle Trip Counts: $\left(R_{0}\right)$ baseline,

$\left(R_{1}\right)$ built environment, and $\left(R_{2}\right)$ land use categories (residential-only sites) ........... 19

Table 9 Negative Binomial Regression Results for Vehicle Trip Counts: (Mo) baseline,

$\left(\mathrm{M}_{1}\right)$ built environment, and $\left(\mathrm{M}_{2}\right)$ land use categories (mixed-use sites) ................. 21

Table 10. Kruskal-Wallis Tests Results ( $p$-values) of the Variation of AM and PM Person

Trip Rates Across Land Use Categories ......................................................... 22

Table 11 Negative Binomial Regression Results for Person Trip Counts: (Ro) baseline,

$\left(R_{1}\right)$ built environment, and $\left(R_{2}\right)$ land use categories (residential-only sites) ........... 24

Table 12 Negative Binomial Regression Results for Person Trip Counts: (Mo) baseline,

$\left(\mathrm{M}_{1}\right)$ built environment, and $\left(\mathrm{M}_{2}\right)$ land use categories (mixed-use sites) .................. 26

Table 13 Accuracy (RMSE and NRMSE) of ITE's Converted Person Trip Rates

Compared with Observed.

\section{LIST OF FIGURES}

Figure 1 How Much Higher are the Observed PersonTrip Rates Compared to Rates

Estimated Using ITE's Converted Rates: (a) Residential and (b) Office 31

Figure 2 How Much Higher are the Observed PersonTrip Rates Compared to Rates

Estimated Using ITE's Converted Rates: (a) Service and (b) Retail 32 


\section{EXECUTIVE SUMMARY}

Cities are increasingly wanting to assess the impacts new development has on all modes in the transportation system. Many communities are requiring site-level transportation impact analysis to examine travel outcomes. The historical focus on developing data and methods exclusively for the automobile, such as the Institute of Transportation Engineers (ITE) Trip Generation Handbook, has left planners with little guidance for these new challenges. This study aims to examine the limitations in the dominant approaches to understand how they may misguide the planning process for multifamily housing development. Specifically, we aim to examine the vehicle and person trip generation rates associated with the land use taxonomies in the ITE Trip Generation Handbook to differentiate between various kinds of residential housing. We ask:

Does the built environment vary across the various ITE Land Use Codes for multifamily housing?

How do vehicle trip rates and newly established person trip rates vary across urban locations?

How well does ITE's recommended practice of converting their vehicle trip rate data to person trip rates perform?

To do this, we conducted a national study of multifamily housing sites that makes use of archived transportation counts and intercept surveys collected on site. The study leveraged several concurrent or recent trip generation studies in Portland, OR; San Francisco, CA; Los Angeles, CA; and Washington, D.C. The data collected from these sites are analyzed using multivariate statistical techniques. This report concludes with a discussion of the implication of these findings for multimodal transportation impact analysis of new development, and policies that aim for better coordination between urban land use change and transportation investments. 


\section{INTRODUCTION AND BACKGROUND}

Methods for assessing the transportation impacts of new development are inadequate, particularly with respect to multimodal transportation. The data and methods available for practice primarily rely on the Institute of Transportation Engineers (ITE) Trip Generation Handbook or trip generation models developed for regional demand forecasting. Both of these approaches have well-documented limitations when applied to urban sites, particularly given the multimodal focus of new urban policies (Clifton et al., 2015; Clifton et al., 2012; Currans \& Clifton, 2015; Shafizadeh et al., 2012; MillardBall, 2015; Weinberger et al., 2014). Research has established that current transportation impact analysis (TIAs) approaches that consider only the demand for private automobiles and are insensitive to urban context tend to underestimate overall transport demand at the site and overestimate future vehicle use. The potential impacts of this issue are numerous, including the inability to adequately plan for the transportation needs of residents, an oversupply of automobile infrastructure and parking and higher costs for developers, which may potentially be passed on to residents.

Given that there is a great need to increase housing supply in the U.S., examining these issues with respect to housing developments more closely is of upmost importance. The growth of housing stock has slowed over time while the number of households has increased. This housing shortage is placing a strain on incomes as prices rise. As workers take on longer commutes in order to access available housing in their price range, urban congestion rises, particularly in locations without alternatives to the automobile.

The construction of multifamily units offers a mechanism to add more units to the housing market with an effective use of land. This additional density has co-benefits beyond easing the housing shortfall. More dense residential development has a lower environmental and fiscal impact as services can be supplied more efficiently, active transportation modes are more readily supported, and when co-located with employment and retail, offers higher accessibility and potentially shorter commutes. Yet current residents resistant to new development, often called NIMBYs (not in my backyard), exploit the shortcomings in the current planning process and TIA methods to provide ammunition for their cause on the grounds of increased traffic.

New data collection methodologies (Clifton et al., 2013; Schneider et al., 2013; Dock et al., 2015; Institute of Transportation Engineers, 2014) expand the information gathered from vehicle trips to include person trips and all modes of transportation. Others have developed methods to adjust ITE's vehicle trip rates to account for urban context or location characteristics (Clifton et al., 2015; Currans \& Clifton, 2015; Clifton et al., 2012), provide a method to evaluate smart growth sites (Schneider et al., 2015) and infill development (Bochner et al., 2011; Daisa et al., 2013). Others are developing entirely new models to estimate vehicle trip rates or non-motorized demand (Institute of 
Transportation Engineers, 2014; Arup, 2015), including local agencies collecting and publishing their own rates (San Francisco Planning Department, 2002; New York City, 2014). Yet many of these are slow to make their way into practice, as the barriers to collecting new data and learning new approaches increase the inertia of continued reliance on the ITE's published data and methods.

This study aims to examine the limitations in the dominant approaches to understand how they may misguide the planning process for multifamily housing development. Specifically, we aim to examine the following questions:

- Q.1. Does the built environment vary across the various ITE Land Use Codes for multifamily housing?

- Q.2. How do vehicle trip rates and newly established person trip rates vary across urban locations?

- Q.3. How well does ITE's recommended practice of converting their vehicle trip rate data to person trip rates perform?

To do this, we conducted a national study of multifamily housing sites that makes use of archived transportation counts and intercept surveys collected on site. The study leveraged several concurrent or recent trip generation studies in Portland, OR; San Francisco, CA; Los Angeles, CA; and Washington, D.C. The data collected from these sites are analyzed using multivariate statistical techniques. This methodology is outlined in the next section. This report concludes with a discussion of the implication of these findings for multimodal transportation impact analysis of new development, and policies that aim for better coordination between urban land use change and transportation investments. 


\section{DATA}

In this section, we describe the data and methods employed to answer the three research questions posed above. We compiled data from four multifamily trip generation studies collected within the past decade and analyzed them with respect to our research questions. These studies, although conducted independently, were instrumental in shaping the most recent standards for practice in the $3^{\text {rd }}$ Edition ITE Trip Generation Handbook (Institute of Transportation Engineers, 2014) and contributed a large amount of data for the recently released $10^{\text {th }}$ Edition ITE Trip Generation Manual (Institute of Transportation Engineers, 2018).

In this study, we consider the implications of both the land use categorization versus contextual variables (built environment measures), comparing in terms of multiple regression performance metrics. In (1), vehicle trip counts are addressed. However, the state of the practice has begun shifting toward person trip counts (coupled with mode share) and so in (2) we also explore the relationship between person trips, land use definition and context.

In (3), we consider ITE's assumed approach of estimated person trips using their suburban vehicle trip counts as a baseline for adjustment. This "converted" trip rate relies on the assumption that (a) we adequately understand the relationship between vehicle and person trip counts collected at ITE's standard locations, and (b) that the estimated person trip rates in suburban locations (ITE's traditional site context) remains constant across contexts. In this section, we explore the implications of these assumptions using the study's compiled residential dataset collected from these four studies listed in Table 1.

Table 1 Sources of Archived Trip Generation Data for Multifamily Housing Used in This Study

\begin{tabular}{|c|c|c|c|c|c|c|c|}
\hline & Study title & Entity & Location & $\begin{array}{l}\# \text { of } \\
\text { sites }\end{array}$ & $\begin{array}{c}\text { \# of } \\
\text { dwelling } \\
\text { units }\end{array}$ & Dates & $\begin{array}{l}\text { Time } \\
\text { Period }\end{array}$ \\
\hline A & $\begin{array}{l}\text { Trip Generation and Data } \\
\text { Analysis Study }\end{array}$ & DDOT & Washington, DC & 56 & 12,274 & $\begin{array}{l}2013 \\
2014 \\
2015\end{array}$ & $\begin{array}{l}\text { 7-10 AM; } \\
\text { 4-7 PM }\end{array}$ \\
\hline B & $\begin{array}{l}\text { Trip Generation Rates for } \\
\text { Transportation Impact } \\
\text { Analyses of Smart Growth } \\
\text { Land Use Projects }\end{array}$ & $\begin{array}{l}\text { University of } \\
\text { California-Davis; } \\
\text { Texas } \\
\text { Transportation } \\
\text { Institute }\end{array}$ & $\begin{array}{l}\text { San Francisco, Los } \\
\text { Angeles, Sacramento, } \\
\text { San Diego (CA) }\end{array}$ & 29 & 7,403 & $\begin{array}{l}2012 \\
2015\end{array}$ & $\begin{array}{l}\text { 7-10 AM; } \\
\text { 6:30-9:30 } \\
\text { AM; 4-7 } \\
\text { PM }\end{array}$ \\
\hline $\mathrm{C}$ & $\begin{array}{l}\text { SF TDM Framework for } \\
\text { Growth }\end{array}$ & Fehrs \& Peers & San Francisco, CA & 16 & 1,741 & 2014 & $\begin{array}{l}\text { 7-10 AM; } \\
\text { 4-7 PM }\end{array}$ \\
\hline $\mathrm{D}$ & Western District ITE & various & $\begin{array}{l}\text { Portland, OR; San } \\
\text { Francisco, CA }\end{array}$ & 5 & 633 & various & \\
\hline
\end{tabular}


We assembled recent trip generation studies that collected multifamily trip generation data (vehicle and/or person trips) from cities in the United States. Each of these studies are independently conducted and often utilize similar methodologies with some variations. The San Francisco study (C), for example, did not collect vehicle occupancy as the purpose of their study was related to mode share and parking. The Western District ITE studies (D) were funded by the Western District ITE group as an annual student group competition. Most of these studies were designed to investigate the relationship between multimodal trip generation rates (person trips, vehicle occupancy, and/or mode share) and the built environment. As such, these studies often tried to control for variations in demographics and thus selected sites from locations with similar incomes ${ }^{1}$.

These trip generation data were augmented with additional information that describes the built environment context for each study location. The nature and sources for these built environment data are provided in Table 2. Descriptive statistics are provided for each of the built environment variables tested in this analysis (see Table 3 ) and the trip generation and transportation impact information (see Table 4); descriptive statistics are segmented by those developments considered "residential-only" and those with mixed use.

It is important to note that these sites were strategically sampled by their respective cities for the purposes of satisfying their own study goals. Thus, it is unclear how these data represent the broader and more varying contexts found in the U.S. (and abroad). While we control for the built environment in our methods, regional variations in accessibility, housing stock, and socio-economics have not been incorporated.

${ }^{1}$ Given this, there is not enough variation in demographics to adequately investigate the relationship of income (or vehicle ownership, etc.) and vehicle or person trips with a high degree of statistical power. 
Table 2 Supplementary Built Environment Data Considered

\begin{tabular}{|c|c|c|c|}
\hline Variable & Variable ID* & Source & Year \\
\hline Population density & $\overline{\mathrm{D} 1 \mathrm{~B}}$ & US Census & 2010 \\
\hline $\begin{array}{l}\text { Activity density (population density }+ \text { employment } \\
\text { density) }\end{array}$ & $\mathrm{D} 1 \mathrm{~B}+\mathrm{D} 1 \mathrm{C}$ & US Census & 2010 \\
\hline 5-tier employment entropy & D2B_E5MIX & EPA & 2010 \\
\hline $\begin{array}{l}\text { Intersection density in terms of auto-oriented } \\
\text { intersections per square mile }\end{array}$ & D3bao & Navteq & 2011 \\
\hline $\begin{array}{l}\text { Distance from population weighted centroid to } \\
\text { nearest transit stop (meters) }\end{array}$ & $\mathrm{D} 4 \mathrm{a}$ & $\begin{array}{r}\text { GTFS, TOD } \\
\text { Database }\end{array}$ & 2012 \\
\hline $\begin{array}{l}\text { Proportion of Census Block Group employment } \\
\text { within } 1 / 4 \text { mile of fixed-guideway transit stop }\end{array}$ & D4b025 & $\begin{array}{l}\text { SLD, TOD } \\
\text { Database }\end{array}$ & 2012 \\
\hline $\begin{array}{l}\text { Proportion of Census Block Group employment } \\
\text { within } 1 / 2 \text { mile of fixed-guideway transit stop }\end{array}$ & D4b050 & $\begin{array}{l}\text { SLD, TOD } \\
\text { Database }\end{array}$ & 2012 \\
\hline $\begin{array}{l}\text { Regional Centrality Index - Auto: Employment } \\
\text { accessibility expressed as a ratio of total MSA } \\
\text { accessibility for the Census Block Group as a ratio of } \\
\text { total MSA accessibility }\end{array}$ & D5cri & EPA & 2010 \\
\hline $\begin{array}{l}\text { Regional Centrality Index - Transit: Employment } \\
\text { accessibility expressed as a ratio of total MSA } \\
\text { accessibility for the Census Block Group as a ratio of } \\
\text { total MSA accessibility }\end{array}$ & D5dri & EPA & 2010 \\
\hline $\begin{array}{l}\text { Median household income for the last } 12 \text { months } \\
\text { (2015 USD) }\end{array}$ & & ACS & 2011-2015 \\
\hline Average household size & & ACS & 2011-2015 \\
\hline Vehicle ownership per driving age adult & & ACS & $2011-2015$ \\
\hline
\end{tabular}

Notes:

All variables measured at the Census Block Group geography level.

${ }^{1 *}$ A portion of this data was compiled from the EPA's Smart Location Database (SLD). Variable names from the SLD are provided for the relevant variables. 
Table 3 Built Environment Descriptive Statistics

\begin{tabular}{|c|c|c|c|c|c|c|}
\hline \multirow[t]{2}{*}{ Variable } & \multicolumn{3}{|c|}{ Residential Only (N=61) } & \multicolumn{3}{|c|}{ Mixed-Use (N=50) } \\
\hline & Mean & Min & Max & Mean & Min & Max \\
\hline Population density & 31.1 & 3.2 & 127.9 & 37.2 & 3.2 & 107.4 \\
\hline $\begin{array}{l}\text { Activity density (population density + employment } \\
\text { density) }\end{array}$ & 66.8 & 16.0 & 448.5 & 116.8 & 24.5 & 525.1 \\
\hline 5-tier employment entropy & 0.7 & 0 & 1.0 & 0.6 & 0.0 & 0.9 \\
\hline $\begin{array}{l}\text { Intersection density in terms of auto-oriented } \\
\text { intersections per square mile }\end{array}$ & 6.2 & 0 & 45.9 & 3.1 & 0.0 & 18.1 \\
\hline $\begin{array}{l}\text { Distance from population weighted centroid to nearest } \\
\text { transit stop (meters) }\end{array}$ & 222 & 22 & 578 & 137 & 16 & 436 \\
\hline $\begin{array}{l}\text { Proportion of Census Block Group employment } \\
\text { within } 1 / 4 \text { mile of fixed-guideway transit stop }\end{array}$ & $51 \%$ & $0 \%$ & $100 \%$ & $55 \%$ & $0 \%$ & $100 \%$ \\
\hline $\begin{array}{l}\text { Proportion of Census Block Group employment } \\
\text { within } 1 / 2 \text { mile of fixed-guideway transit stop }\end{array}$ & $83 \%$ & $0 \%$ & $100 \%$ & $98 \%$ & $1 \%$ & $100 \%$ \\
\hline $\begin{array}{l}\text { Regional Centrality Index - Auto: Employment } \\
\text { accessibility expressed as a ratio of total MSA } \\
\text { accessibility for the Census Block Group as a ratio of } \\
\text { total MSA accessibility }\end{array}$ & 0.68 & 0.35 & 0.98 & 0.84 & 0.56 & 1.00 \\
\hline $\begin{array}{l}\text { Regional Centrality Index - Transit: Employment } \\
\text { accessibility expressed as a ratio of total MSA } \\
\text { accessibility for the Census Block Group as a ratio of } \\
\text { total MSA accessibility }\end{array}$ & 0.38 & 0.04 & 0.98 & 0.54 & 0.28 & 0.92 \\
\hline $\begin{array}{l}\text { Median household income for the last } 12 \text { months } \\
\text { (2015 USD) }\end{array}$ & $\$ 74,694$ & $\$ 13,598$ & $\$ 250,000$ & $\$ 98,850$ & $\$ 42,361$ & $\$ 149,475$ \\
\hline Average household size & 1.95 & 1.12 & 3.33 & 1.86 & 1.40 & 2.89 \\
\hline Vehicle ownership per driving age adult & 0.58 & 0.38 & 0.89 & 0.58 & 0.42 & 0.76 \\
\hline
\end{tabular}

Notes:

All variables measured at the Census Block Group geography level. 
Table 4 Descriptive Statistics of Trip Generation and Transportation Impacts

\begin{tabular}{|c|c|c|c|c|c|c|}
\hline \multirow{2}{*}{ Variable } & \multicolumn{3}{|c|}{ Residential Only (N=61*) } & \multicolumn{3}{|c|}{ Mixed-Use $(\mathrm{N}=50)$} \\
\hline & Mean & Min & Max & Mean & Min & Max \\
\hline \multicolumn{7}{|l|}{ AM Peak Hour } \\
\hline Automobile Trips & 53 & 2 & 225 & 81 & 2 & 261 \\
\hline Person Trips & 111 & 9 & 425 & 292 & 37 & 1018 \\
\hline Automobile Occupancy & 1.2 & 1.0 & 1.6 & 1.2 & 1.0 & 1.5 \\
\hline \multicolumn{7}{|l|}{ Mode Share } \\
\hline Automobile & $53 \%$ & $5 \%$ & $94 \%$ & $35 \%$ & $6 \%$ & $68 \%$ \\
\hline Transit & $15 \%$ & $0 \%$ & $62 \%$ & $16 \%$ & $0 \%$ & $45 \%$ \\
\hline Walking & $28 \%$ & $4 \%$ & $83 \%$ & $46 \%$ & $16 \%$ & $82 \%$ \\
\hline Biking & $3 \%$ & $0 \%$ & $13 \%$ & $2 \%$ & $0 \%$ & $7 \%$ \\
\hline \multicolumn{7}{|l|}{ PM Peak Hour } \\
\hline Automobile Trips & 49 & 1 & 240 & 83 & 1 & 402 \\
\hline Person Trips & 113 & 11 & 468 & 421 & 34 & 1340 \\
\hline Automobile Occupancy & 1.3 & 1.0 & 3.0 & 1.4 & 1.0 & 2.8 \\
\hline \multicolumn{7}{|l|}{ Mode Share } \\
\hline Automobile & $49 \%$ & $0 \%$ & $91 \%$ & $28 \%$ & $2 \%$ & $68 \%$ \\
\hline Transit & $13 \%$ & $0 \%$ & $59 \%$ & $14 \%$ & $2 \%$ & $41 \%$ \\
\hline Walking & $35 \%$ & $5 \%$ & $82 \%$ & $55 \%$ & $20 \%$ & $90 \%$ \\
\hline Biking & $3 \%$ & $0 \%$ & $14 \%$ & $3 \%$ & $0 \%$ & $7 \%$ \\
\hline
\end{tabular}

Notes:

* For the PM peak hour, only 44 out of 61 residential-only sites 


\section{Q.1. DOES THE BUILT ENVIRONMENT VARY ACROSS THE VARIOUS ITE LAND USE CODES FOR MULTIFAMILY HOUSING?}

ITE's Trip Generation Handbook (9 $9^{\text {th }}$ Edition) provides data for 19 different categories of residential land uses, including single-family detached housing (Land Use Code 210) (Institute of Transportation Engineers, 2012). Six of the multifamily residential land use categories for multifamily ${ }^{2}$ examined in this research are listed below with their ITE land use code (LUC) and described Table 5:

- 220 Apartment (unspecified scale)

- 221 Low-Rise Apartment

- 222 Mid-Rise Apartment

- 223 High-Rise Apartment

- 230 Residential Condominium/Townhouse (unspecified scale)

- 231 Low-Rise Residential Condominium/Townhouse

- 232 High-Rise Residential Condominium/Townhouse

The first category LUC 220 is general apartment with no specification of building height. The primary difference between this category and the next three categories (LUC 221, 221 , and 223) is the intensity or scale of the development (number of floors). The last three categories differ from the first four in that they are condominiums. In these sites, individual units are privately owned; however, residents may be owners or rent from the owner. LUC 230 is general condominium with no scale specified. The last two categories (LUC 231 and 232) also differentiate the land use intensities (similar to LUC 221 and LUC 222) in addition to the ownership issue. All of the vehicle trip generation data provided for these land use codes are provided as a function of the number of units (trips/housing unit). For these residential housing categories, including detached singlefamily dwellings, the trip generation data are reported graphically as a function of the number of dwelling units or provided as an average rate (trips per dwelling unit).

The ITE Trip Generation Handbook does not provide any explicit rationale for why the number of vehicle or person trips made per housing unit (single-family or apartments) would be different with an increase in scale. In general, the process for adding new land use codes comes from anecdotal evidence that rates may/could be different and are determined to be statistically different using basic hypothesis tests. One possible rationale is that for some land uses, there is an economy of scale and that there are fewer visitors to the site (e.g., one mail delivery serves an entire apartment building

2 The other residential uses include: 224 Rental Townhouse, 233 Luxury Condominium/Townhouse, 240 Mobile Home Park, 251 Senior Adult Housing - Detached, 252 Senior Adult Housing —Attached, 253 Congregate Care Facility, 254 Assisted Living, 255 Continuing Care Retirement Community, 260 Recreational Homes, 265 Timeshare, 270 Residential Planned Unit. The $10^{\text {th }}$ Edition handbook, published after this analysis was completed, made changes to the land use codes after removing data collected prior to 1980 to correct for some of the ambiguities in the land use definitions. For example, the numbered order of the intensity of land uses was reordered to align with the natural ordinal relationship between intensities (i.e., from 'low-', 'high-', then 'mid-'rise to 'low-', 'mid-', then 'high-'rise). 
versus an additional mail trip for each single-family dwelling; or internal capture of social trips between residents of the same building). Another theory is that an increase in development intensity tends to happen in locations that are more urbanized (i.e., more density) because land markets are more competitive and, thus, it is this difference in urban context that leads to differences in trip rates. For example, higher-intensity developments are more likely to occur in locations that are more walkable, bikable and well served by transit. The mixed-use development may benefit from internal capture residents visiting the ground-floor land uses - but may also have more trips generated from non-resident visitors to these commercial uses. Thus, one might expect lower vehicle and person trip rates for these sites. 


\begin{tabular}{lll}
\hline LUC & Name & \multicolumn{1}{c}{ Description } \\
\hline Apartment & $\begin{array}{l}\text { Apartments are rental dwelling units located within the same building with at least } \\
\text { three other dwelling units, for example, quadraplexes and all types of apartment } \\
\text { buildings. The studies included in this land use did not identify whether the apartments } \\
\text { were low-rise, mid-rise, or high-rise. Low-rise apartment (Land Use 221), high-rise } \\
\text { apartment (Land Use 222) and mid-rise apartment (Land Use 223) are related uses. }\end{array}$ \\
& $\begin{array}{l}\text { Low-rise apartments (rental dwelling units) are units located in rental buildings that } \\
\text { have one or two levels (floors), such as garden apartments. Apartment (Land Use } \\
\text { 220), high-rise apartment (Land Use 222) and mid-rise apartment (Land Use 223) } \\
\text { are related uses. }\end{array}$
\end{tabular}

222 High-Rise Apartment

High-rise apartments (rental dwelling units) are units located in rental buildings that have more than 10 levels (floors) and most likely have one or more elevators. Apartment (Land Use 220), low-rise apartment (Land Use 221) and mid-rise apartment (Land Use 223) are related uses.

Mid-rise apartments are apartments (rental dwelling units) in rental buildings that

223 Mid-Rise Apartment have between three and 10 levels (floors). Apartment (Land Use 220), low-rise apartment (Land Use 221) and high-rise apartment (Land Use 222) are related uses.

Residential condominiums/townhouses are defined as ownership units that have at least one other owned unit within the same building structure. Both condominiums and townhouses are included in this land use. The studies in this land use did not

230 Residential Condominium identify whether the condominiums/townhouses were low-rise or high-rise. Low-rise residential condominium/townhouse (Land Use 231), high-rise residential condominium/townhouse (Land Use 232) and luxury condominium/townhouse (Land Use 233) are related uses.

Low-rise residential condominiums/townhouses are units located in buildings that

Low-Rise Residential Condominium

232
High-Rise Residential Condominium have one or two levels (floors). Both condominiums and townhouses are included in this land use. Residential condominium/townhouse (Land Use 230), high-rise residential condominium/townhouse (Land Use 232) and luxury condominium/townhouse (Land Use 233) are related land uses.

High-rise residential condominiums/townhouses are units located in buildings that have three or more levels (floors). Both condominiums and townhouses are included in this land use. Residential condominium/townhouse (Land Use 230), low-rise residential condominium/ townhouse (Land Use 231) and luxury condominium/townhouse (Land Use 233) are related land uses.

The differences in travel impacts between apartments and condominiums are less clear. "Ownership" may be a proxy for higher income. Travel behavior research has established a positive association with income, specifically related to higher rates of auto ownership (Pucher \& Renne, 2003; Giuliano \& Dargay, 2006; Blumenberg \& 
Pierce, 2012), lower propensity to travel regularly by public transit (Giuliano, 2005) and walking (Pucher \& Renne, 2003; Tal \& Handy, 2010). However, it would be difficult to tell whether residents of condos are the owners of the unit or renters. Further, it is difficult to test these differences and thus is not the focus of this analysis.

These distinct residential land use categories become an indirect proxy for built environment (or socioeconomic, employment status, age, and disability, in the case of some of the categories in the footnote) among the residents of these housing types that impact trip making. The relationship between the built environment and travel behavior has long been investigated in the research literature (e.g., Ewing and Cervero 2010); however, the trip generation methodologies have been slow to incorporate them directly. Because ITE does not publish location information or descriptions of the urban contexts of each site, issues related to whether these indirect land use categories adequately capture these behavioral influences in their trip rates have not been explored.

To understand whether these categories actually serve as good proxies for the built environment, each of the sites included in the studies in Table 1 was categorized in their appropriate ITE LUC category. For sites where adequate information was not available to categorize land uses into a specific site scale (e.g., high-rise), these were included either in category LUC 220 or LUC 230, as appropriate. After appending built environment information for each of these sites (see Table 2) to each study location, the relationship between LUC and the built environment was tested using statistical analysis.

This analysis tests whether the ITE residential land use categories (e.g., high-rise, midrise, low-rise) improve the variation of context being captured compared to the built environment. This analysis does not incorporate any transportation outcomes as yet, but instead focuses on the built environment as observed among each category of land use. Here, the hypothesis that the built environment does not vary across ITE's land use definitions is tested:

\section{$H_{o}$ : Various measures of the built environment do not vary across ITE's land use categories.}

$H_{a}$ : Various measures of the built environment do vary across ITE's land use categories.

The ANOVA was selected as the statistical test to allow for comparison of statistical variation of values of the built environment measures (activity density, population density, employment density, and intersection density) between the sites grouped by ITE land use code. Following, a Tukey post-hoc "Honest Significant Difference" test is explored to determine which categories are significantly different from each other.

The results, shown in

Table 6 , indicated that the density values varied significantly by land use category $(p<0.001)$; however, transit access was not significant. A Tukey post-hoc analysis showed that the defined LUCs had significantly different activity, population, and employment density values, but also that there was not enough evidence to find 
significance across all pairings of land use categories. This suggests that at least some of the residential land use codes serve as a proxy for the built environment, but not all of them.

Table 6 ANOVA and Tukey Post-Hoc Tests of Variation in Built Environment Across ITE Land Use Codes for Multifamily Residential

\begin{tabular}{|c|c|c|c|c|c|}
\hline & \multicolumn{5}{|c|}{ Built Environment Measures } \\
\hline & $\begin{array}{l}\text { Activity } \\
\text { Density }\end{array}$ & $\begin{array}{l}\text { Population } \\
\text { Density }\end{array}$ & $\begin{array}{c}\text { Employment } \\
\text { Density }\end{array}$ & $\begin{array}{l}\text { Intersection } \\
\text { Density }\end{array}$ & $\begin{array}{c}\% \text { within } \\
1 / 4 \text { mi of } \\
\text { Transit }\end{array}$ \\
\hline ANOVA p-value & $<0.001$ & $<0.001$ & $<0.001$ & --- & --- \\
\hline Land Use Category (ITE Code 9th Edition) & Tukey P & t-Hoc Signifi & ficance Betwe & en LUC Pairs & (p-value) \\
\hline High-Rise Apt. (222)-Apt. (220) & --- & --- & $<0.20$ & $<0.20$ & --- \\
\hline Mid-Rise Apt. (223)-Apt. (220) & --- & $<0.001$ & --- & --- & --- \\
\hline Condo (230)-Apt. (220) & --- & --- & --- & --- & --- \\
\hline High-Rise Condo (232)-Apt. (220) & $<0.001$ & --- & $<0.001$ & --- & --- \\
\hline Mid-Rise (223)-High-Rise Apt. (222) & --- & --- & --- & $<0.20$ & --- \\
\hline Condo (230)-High-Rise Apt. (222) & --- & --- & --- & --- & --- \\
\hline High-Rise Condo (232)-High-Rise Apt. (222) & $<0.01$ & --- & $<0.01$ & --- & --- \\
\hline Condo (230)-Mid-Rise Apt. (223) & --- & --- & --- & --- & --- \\
\hline High-Rise Condo (232)-Mid-Rise Apt. (223) & $<0.001$ & --- & $<0.001$ & --- & --- \\
\hline High-Rise Condo (232)-Condo (230) & $<0.001$ & --- & $<0.001$ & --- & --- \\
\hline
\end{tabular}

NOTES: ---: not significant ( $\mathrm{p}$-value $>0.2$ )

The next question explores whether these different categories and contexts reveal different associations in models of trip generation. If so, it may be preferable to have one aggregate multifamily land use category with different categories of built environment. 


\section{Q.2. HOW DO VEHICLE AND PERSON TRIP RATES FOR MULTIFAMILY HOUSING VARY ACROSS URBAN LOCATIONS?}

In this section, we expand upon the findings from the previous section to test whether demand, as measured by vehicle and person trip rates (trips per dwelling unit), vary by ITE's residential land use categories. The hypothesis that trip rates vary (vehicle and person trips) is expressed as follows:

$H_{0}$ : Vehicle (Person) trip rates do not vary across ITE's land use categories.

$H_{a}$ : Vehicle (Person) trip rates do vary across ITE's land use categories.

This hypothesis was tested using two different statistical analysis techniques: 1) Krushkal-Wallis Analysis of Variance and 2) negative binomial regression. The KruskalWallis (KW) analysis of variance was employed to examine variations in trip counts (vehicle and person) across land use categories. This method is similar to the ANOVA but developed for nonparametric (non-normally distributed) data, such as count data.

To explore if ITE's LUC offer better explanatory power in the variation of trip rates over the direct built environment measures, we apply a negative-binomial regression analysis. Negative binomial regressions account for the count-based, non-negative, non-normally distributed nature of the data ${ }^{3}$. The model is estimated as:

$$
\ln (Y)=\beta_{0}+\boldsymbol{\beta}_{\boldsymbol{k}} \boldsymbol{X}_{\boldsymbol{k}},
$$

where the (vehicle or person) counts, $Y$, for establishments are regressed upon the $k$ number independent variables, $X$. Predicted values can be computed using the following equation(s):

$$
\begin{gathered}
\hat{y}_{i}=\exp \left(\boldsymbol{\beta}_{\boldsymbol{k}} \boldsymbol{X}_{\boldsymbol{k}}+\beta_{0}\right), \text { or } \\
\hat{y}_{i}=\exp \left(\boldsymbol{\beta}_{\boldsymbol{k}} \boldsymbol{X}_{\boldsymbol{k}}\right) * \exp \left(\beta_{0}\right)
\end{gathered}
$$

Fifty of the sites included mixed use and, thus, analysis was segmented accordingly into: (1) residential only, and (2) mixed use.

For the residential-only analysis, three sets of (vehicle and person) trip generation models were estimated for both AM and PM peak period counts: $\left(R_{0}\right)$ a baseline model, $\left(R_{1}\right)$ using context as an independent descriptor, $\left(R_{2}\right)$ and using ITE's LUC categories.

\footnotetext{
${ }^{3}$ In similar studies (Institute of Transportation Engineers, 2014; Schneider, et al., 2013), counts are transformed using a natural log to normalize the data before regressing them upon the independent variables using a linear model. When these models are used for predictive purposes, they often suffer from a de-transformation bias, which occurs when the de-transformation of the outcome variable does not account for the necessary detransformation of the error term (Wang \& Currans, 2018). To circumvent this, we apply a model intended to work with the count-based nature of the data-negative-binomial regression-in order to avoid this bias if used predictively.
} 
For each peak period and for both vehicle and person trip counts, the following models were estimated:

Base model $\left(R_{0}\right):$ Trips $_{\text {peak }}=\beta_{0}+\beta_{1} D U$, Context model $\left(R_{1}\right)$ : Trips $_{\text {peak }}=\beta_{0}+\beta_{1} D U+\beta_{l}$ Context $_{c}$, LUC model $\left(R_{2}\right):$ Trips $_{\text {peak }}=\beta_{0}+\beta_{1} D U+\beta_{m} L U C_{m}$,

Where:

$D U$ is the number of dwelling units;

$L U C_{m}$ are dummy variables representing the $l^{\text {th }}$ land use category out of $L$ categories;

Context $c_{c}$ includes the $c^{\text {th }}$ built environment variable of provided in Table 2 in the Data section; and

$\beta_{0}, \beta_{1}, \beta_{c}, \beta_{l}$ are the estimated parameters.

Although multiple contextual variables are tested in the models, only the variables with the highest level of significance are retained. ${ }^{4}$

A similar analysis method was used for the mixed-use sites. For both vehicle and person trip counts, three sets of models were estimated for both AM and PM peak period counts: $\left(M_{0}\right)$ a baseline model, $\left(M_{1}\right)$ one using context as an independent descriptor, and $\left(M_{2}\right)$ one using ITE's land use codes (LUC) categories. For each peak period and for both vehicle and person counts, the following models were estimated:

Base model $\left(M_{0}\right)$ : Trips $_{\text {peak }}=\beta_{0}+\beta_{1} D U+\beta_{2} S Q F T+\beta_{3} H U$, Context model $\left(M_{1}\right)$ :Trips peak $=\beta_{0}+\beta_{1} D U+\beta_{2}$ SQFT $+\beta_{3} H U+\beta_{l}$ Context $_{c}$, LUC model $\left(M_{2}\right):$ Trips $_{\text {peak }}=\beta_{0}+\beta_{1} D U+\beta_{2} S Q F T+\beta_{3} H U+\beta_{l} L U C_{l}$,

Where:

$D U$ is the number of dwelling units;

$S Q F T$ is the gross retail square footage in each mixed-use site;

$\mathrm{HU}$ includes the number of hotel units in each location;

$L U C_{l}$ are dummy variables representing the $l^{\text {th }}$ land use category out of $L$ categories;

Context $t_{c}$ includes the $c^{\text {th }}$ built environment variable of provided in Table 2; and $\beta_{0}, \beta_{1}, \beta_{2}, \beta_{3}, \beta_{c}$, and $\beta_{l}$ are the estimated parameters

Although multiple contextual variables are tested, only the model indicating the highest level of significance is retained. ${ }^{4}$ Only one observed location in this dataset includes hotel units; although this data point is included in the regression, the coefficient derived

\footnotetext{
${ }^{4}$ As described in the Section 2 Data, the LUCs consider both scale of housing - which relates to the built environment and density - as well as ownership in terms of condominium and rentals. Ownership may also be an indication of income, so a variable for median income of the surrounding area was also tested. There was not enough evidence to suggest income or ownership to be significant in any model tested, and therefore, we do not include them in the methods description, results, or discussion.
} 
from this analysis should only be used as a control for potential variation from that point and not as an indication of an actual rate.

For both sets of models, three tests were used to compare the performance of the LUC with built environment measurements ${ }^{5}$ : (1) Akaike Information Criterion (AIC); (2) likelihood ratio (LR) test; and (3) the (normalized) root mean square error (N)RMSE. These are described below.

The Akaike Information Criterion (AIC) is an estimator of relative quality of models that can be used to compare models of similar datasets (with similar outcome variables) across one another. Models with lower AIC values indicate those with a better fit. Models that include additional variables that do not statistically improve the model are penalized with increasing AIC values. Although AIC is commonly computed within statistical software as a measure of fit or quality of the estimation of non-linear models, it can be computed numerically as follows:

$$
A I C=2 k-2 \ln (\hat{L}),
$$

Where;

$k$ is the number of parameters in the model and

$\hat{L}$ is the maximum value of the likelihood function $\left(\hat{L}=P(x \mid \hat{\theta})_{\max }\right.$ where $\hat{\theta}$ denotes the parameters estimated that maximize the function).

The AIC was used to compare the three models in each set (residential or mixed use, AM or PM peak model suites). A lower AIC is an indication of a better fitting model.

The likelihood ratio (LR) test is commonly used to compare the goodness of fit for two different models where one of the two models is a restricted (alternative) version of the other (null). This test can be used to determine whether one model with additional constraints (variables/coefficients) has statistically superior fit than the other. The test statistic is estimated as:

$$
D=2 *[\ln (\text { likelihood for alternative model })-\ln (\text { likelihood for null model })] .
$$

The test statistic, D, is then located along the probability distribution of the test statistic-a chi-squared distribution with $\left(d f_{\text {alt }}-d f_{\text {null }}\right)$ degrees of freedom to determine significance. Significance indicates that the alternative model (with additional parameters compared with the null model) is a significant improvement over the null model.

\footnotetext{
5 One common way to evaluate linear regression - particularly when comparing models made from the same dataset and using the same outcome variables - is using the ever-popular coefficient of variation $\mathrm{R}^{2}$. However, when estimating and comparing count-based models, this traditional method of regression evaluation cannot be estimated. Psuedo- $\mathrm{R}^{2}$ measures, while useful, often underestimate the comparative levels of variation explained as traditional approaches to evaluation, making models seem weaker although they are better theoretical fits.
} 
The LR test is used to compare the significant contribution of additional parameters. In this analysis, we use the LR test to compare the improvement of the model versus the base case (e.g., $R_{1}$ versus $R_{0}$, or $M_{2}$ versus $M_{0}$ ).

The NRMSE and RMSE measures indicate the amount of difference between the predicted values of the outcome variable $(\hat{y})$ and the observed values of the outcome variable $(y)$. RMSE and NRMSE are similar in that they both include the root of the average squared deviations, as described here quantitatively:

$$
R M S E=\operatorname{sqrt}\left(\frac{\sum_{i=1}^{N}(\hat{y}-y)^{2}}{N}\right) .
$$

However, NRMSE normalizes the RMSE by the range of observed values of $y$. Similar levels of RMSE for cases where the range of outcome variables is either large or small, would indicate vary different things. For cases where large amounts of variation are observed, a RMSE would appear smaller in contrast. Similarly, in cases where there is low variation in the outcome variable, $y$, one would expect higher RMSE values to indicate greater levels of difference. As such, we consider both RMSE and NRSME, as quantitatively defined below, to compare model performance:

$$
N R M S E=\operatorname{sqrt}\left(\frac{\sum_{i=1}^{N}(\hat{y}-y)^{2}}{N}\right) /\left(y_{\max }-y_{\min }\right) .
$$

Both the RMSE and NMSE are used in this analysis to compare the relative predictive accuracy of the models - or the difference between predictive and observed values. Smaller RMSE or NMSE values indicate the model predictions are closer to the observed values.

\section{VEHICLE TRIP RATES - RESIDENTIAL-ONLY SITES}

The results of the KW tests for vehicle trip data for the AM and PM peak hour are shown in Table 7. The results indicate there is enough evidence to suggest significant variation $(p<0.1)$ between mid-rise apartments (LUC 223) and high-rise apartments (LUC 222) and apartments (LUC 220) and condos (230) during the AM peak period. In the PM peak period, results show a significant variation in trip rates between mid-rise apartments (LUC 223) and apartments (LUC 220) during the PM peak period. Due to low sample sizes in LUC 222, 230, and 232, this finding should not be taken as conclusive findings for those land uses but rather suggestive of a trend. Also note that LUC 220 and LUC 230 are a general category with no information about scale (height) of the development. 
Table 7. Kruskal-Wallis Tests Results (p-values) of the Variation of AM and PM Vehicle Trip Rates Across Land Use Categories

\begin{tabular}{|c|c|c|c|c|c|c|}
\hline & \multicolumn{5}{|c|}{ AM Peak Hour } & \multirow[b]{2}{*}{$\begin{array}{l}\text { Sample } \\
\text { Size (N) }\end{array}$} \\
\hline & $\begin{array}{l}\text { Mid-Rise Ap } \\
\text { (223) }\end{array}$ & $\begin{array}{l}\text { t. High-Rise Apt. } \\
\text { (222) }\end{array}$ & $\begin{array}{l}\text { High-Rise Condo } \\
\text { (232) }\end{array}$ & $\begin{array}{l}\text { Apt. } \\
(220)\end{array}$ & $\begin{array}{l}\text { Condo } \\
(230)\end{array}$ & \\
\hline Mid-Rise Apt. (223) & --- & & & & & 24 \\
\hline High-Rise Apt. (222) & 0.01 & --- & & & & 4 \\
\hline High-Rise Condo (232) & 0.50 & 0.64 & --- & & & 2 \\
\hline Apt. (220) & 0.00 & 0.53 & 0.80 & --- & & 28 \\
\hline \multirow[t]{3}{*}{ Condo (230) } & $\mathbf{0 . 0 3}$ & 0.29 & 1.00 & 0.95 & --- & 3 \\
\hline & \multicolumn{5}{|c|}{ PM Peak Hour } & \\
\hline & $\begin{array}{c}\text { Mid-Rise Ap } \\
\text { (223) }\end{array}$ & $\begin{array}{l}\text { t. High-Rise Apt. } \\
\text { (222) }\end{array}$ & $\begin{array}{l}\text { High-Rise Condo } \\
\qquad(232)\end{array}$ & $\begin{array}{l}\text { Apt. } \\
(220)\end{array}$ & $\begin{array}{c}\text { Condo } \\
(230)\end{array}$ & $\begin{array}{l}\text { Sample } \\
\text { Size (N) }\end{array}$ \\
\hline Mid-Rise Apt. (223) & --- & & & & & 24 \\
\hline High-Rise Apt. (222) & 0.39 & --- & & & & 4 \\
\hline High-Rise Condo (232) & 0.50 & 1.00 & --- & & & 2 \\
\hline Apt. (220) & $\mathbf{0 . 0 0}$ & 0.73 & 0.74 & --- & & 28 \\
\hline Condo (230) & 0.19 & 1.00 & 1.00 & 0.50 & --- & 3 \\
\hline
\end{tabular}

Note: Bold values are significant at the 0.1 level

Next, the results of the negative binomial models of the vehicle trips rates are shown in Table 8. Each of the built environment variables from Table 2 were tested in each of these models; however, the only significant variables identified for these residential-only locations were population density and the proportion of the surrounding population within a quarter mile to transit.

The results and model performance for both $\mathrm{AM}$ and PM peak hour models were similar. In the two peak periods, both $R_{1}$ and $R_{2}$ improved significantly upon the base model $R_{0}-$ Model $R_{2}$ more so than $R_{1}$. Similarly, Model $R_{2}$ had a slightly lower AIC than $\mathrm{R}_{1}$. However, when comparing RMSE and NRMSE, in both cases $\mathrm{R}_{1}$ produced better results suggesting the built environment may capture more variation than the LUC definition specifying the intensity of development.

These results suggest that, for both the AM and PM peak periods, the use of the LUC slightly improves the model performance (in terms of the AIC and LR test) over the built environment measures and thus may be a better predictor than simple built environment measures. However, these results do not suggest that the LUC model has a smaller 


\section{difference between predicted and observed values than the mode using built environment variables.}

Table 8 Negative Binomial Regression Results for Vehicle Trip Counts: (Ro) baseline, $\left(R_{1}\right)$ built environment, and $\left(R_{2}\right)$ land use categories (residential-only sites)

\begin{tabular}{|c|c|c|c|c|c|c|}
\hline & \multicolumn{3}{|c|}{ AM PEAK } & \multicolumn{3}{|c|}{ PM PEAK } \\
\hline & $\mathrm{R}_{0}$ & $\mathrm{R}_{1}$ & $\mathrm{R}_{2}$ & $\mathrm{R}_{0}$ & $\mathrm{R}_{1}$ & $\mathrm{R}_{2}$ \\
\hline \multicolumn{7}{|l|}{ No. of Dwelling Units } \\
\hline coeff. & 0.005 & 0.004 & 0.004 & 0.005 & 0.004 & 0.004 \\
\hline std. error & -0.001 & -0.001 & -0.001 & -0.001 & -0.001 & -0.001 \\
\hline sig. & $p=0.000^{* * *}$ & $\mathrm{p}=0.000 * * *$ & $\mathrm{p}=0.000 * * *$ & $p=0.000 * * *$ & $\mathrm{p}=0.000^{* * *}$ & $p=0.000 * * *$ \\
\hline \multicolumn{7}{|l|}{ Population Density } \\
\hline coeff. & --- & -0.011 & --- & --- & -0.009 & --- \\
\hline std. error & & -0.004 & & & -0.004 & \\
\hline sig. & & $\mathrm{p}=0.004 * * *$ & & & $p=0.016 * *$ & \\
\hline \multicolumn{7}{|c|}{$\begin{array}{l}\% \text { Population in Block Group } \\
\text { within } 1 / 4 \text { mile of Transit }\end{array}$} \\
\hline coeff. & --- & 0.439 & --- & --- & 0.403 & --- \\
\hline std. error & & -0.240 & & & -0.241 & \\
\hline sig. & & $p=0.068 *$ & & & $p=0.095 *$ & \\
\hline \multicolumn{7}{|l|}{ High-Rise Apt. LUC 222} \\
\hline coeff. & --- & --- & 0.134 & --- & --- & 0.517 \\
\hline std. error & & & -0.300 & & & -0.289 \\
\hline sig. & & & $p=0.655$ & & & $p=0.074 *$ \\
\hline \multicolumn{7}{|l|}{ Mid-Rise Apt. LUC 223} \\
\hline coeff. & --- & --- & 0.706 & --- & --- & 0.715 \\
\hline std. error & & & -0.170 & & & -0.166 \\
\hline sig. & & & $\mathrm{p}=0.000 * * *$ & & & $\mathrm{p}=0.000 * * *$ \\
\hline High-Rise Condo LUC 230 & --- & --- & 0.231 & --- & --- & 0.420 \\
\hline coeff. & & & -0.341 & & & -0.330 \\
\hline $\begin{array}{l}\text { std. error } \\
\text { sig. }\end{array}$ & & & $p=0.499$ & & & $p=0.204$ \\
\hline \multicolumn{7}{|l|}{ High-Rise Condo LUC 232} \\
\hline coeff. & --- & --- & 0.103 & --- & --- & 0.104 \\
\hline std. error & & & -0.415 & & & -0.406 \\
\hline sig. & & & $p=0.804$ & & & $p=0.798$ \\
\hline \multicolumn{7}{|l|}{ Constant } \\
\hline coeff. & 2.783 & 2.966 & 2.569 & 2.781 & 2.914 & 2.546 \\
\hline std. error & -0.135 & -0.197 & -0.128 & -0.133 & -0.197 & -0.125 \\
\hline sig. & $p=0.000^{* * *}$ & $\mathrm{p}=0.000 * * *$ & $\mathrm{p}=0.000 * * *$ & $p=0.000 * * *$ & $\mathrm{p}=0.000^{* * *}$ & $p=0.000 * * *$ \\
\hline Observations & 61 & 61 & 61 & 61 & 61 & 61 \\
\hline Log Likelihood & -279.393 & -274.764 & -270.398 & -275.964 & -272.543 & -266.89 \\
\hline Theta & $2.620^{* * *}(0.506)$ & $3.080^{* * *}(0.613)$ & $3.591^{* * *}(0.733)$ & \multicolumn{2}{|c|}{$2.704^{* * *}\left(0.543^{\prime} 3.071^{* * *}(0.634)\right.$} & $3.824 * * *(0.828)$ \\
\hline LR (R0 vs. R1) & & \multicolumn{3}{|c|}{$\mathrm{Chi}^{2}: 6.80(\mathrm{p}$-value $<0.05)$} \\
\hline LR (R0 vs. R2) & \multicolumn{3}{|c|}{$\begin{array}{l}\text { Chi }^{2}: 9.26(p \text {-value }<0.01) \\
\text { Chi }^{2}: 17.99(p-\text { value }<0.001)\end{array}$} & $\mathrm{Chi}^{2}: 18.10(p-v$ & $e<0.01)$ & \\
\hline RMSE & 106.90 & 61.10 & 92.20 & 76.00 & 46.20 & 57.30 \\
\hline NRMSE & 0.48 & 0.27 & 0.41 & 0.32 & 0.19 & 0.24 \\
\hline Akaike Inf. Crit. & 562.787 & 557.527 & 552.797 & 555.927 & 553.086 & 545.781 \\
\hline
\end{tabular}




\section{VEHICLE TRIP RATES - MIXED-USE SITES}

While the residential-only analysis explored variation in the built environment and trip rates across land use categories, the introduction of mixed-use sites complicates the ability to explain trip generation. These sites, mainly collected from Washington, D.C., include residential locations - categorized similarly as in ITE-as well as retail, defined as either neighborhood-serving (i.e., convenience land uses) and destination-retail (i.e., non-convenience, major chains). This complication prevents the use of the $\mathrm{KW}$ analysis of variance tests for these sites, and therefore this method is not applied to these sites.

Instead, we estimate two sets of negative binomial regressions models (see

Table 9) —one for the AM peak period and one for the PM peak. Each set includes three models, similar to the residential-only sites: $\left(\mathrm{M}_{0}\right)$ the base case with only site size variables; $\left(M_{1}\right)$ the base case with built environment indicators; and $\left(M_{2}\right)$ the base case with LUC indicators. For both AM and PM models, the proportion of the population in the surrounding area near 0.25 miles to transit and the population density had the highest level of significance of all built environment measures tested (although not marginally significant). For models $M_{1}$ and $M_{2}$ for both peak periods, results do not provide evidence to suggest significant relationships for either the LUC variables nor the built environment variables. Neither model performs as well as the base model, $\mathrm{Mo}$, which only includes dwelling units and retail square footage. No built environment variables tested (see Table 2 for a list of variables) were identified to have a significant relationship.

There are several potential reasons for these findings. Travel to the residential portion of the sites and travel to the retail portion were not differentiated in these data. Also, all the mixed-use sites were located in Washington, D.C.; there also may not be enough variation in the independent variables to result in significant relationships for the built environment variables.

In terms of the estimated coefficients, it is worth noting that although the relationship between vehicle trip rates and retail square footage is significant for both peak periods - and the effect size is nearly twice as large for the PM versus the AM peak period - the constant term for AM peak models is slightly higher than the PM peak period. The coefficients estimated for the relationship between the number of dwelling units and vehicle trip rates for both periods is relatively constant across all models. 
Table 9 Negative Binomial Regression Results for Vehicle Trip Counts: (Mo) baseline, $\left(M_{1}\right)$ built environment, and $\left(M_{2}\right)$ land use categories (mixed-use sites)

\begin{tabular}{|c|c|c|c|c|c|c|}
\hline & \multicolumn{3}{|c|}{ AM PEAK } & \multicolumn{3}{|c|}{ PM PEAK } \\
\hline & $M_{0}$ & $M_{1}$ & $M_{2}$ & $M_{0}$ & $\mathrm{M}_{1}$ & $M_{2}$ \\
\hline \multicolumn{7}{|l|}{ No. of Dwelling Units } \\
\hline coeff. & 0.004 & 0.004 & 0.004 & 0.003 & 0.003 & 0.004 \\
\hline std. error & 0.001 & 0.001 & 0.001 & 0.001 & 0.001 & 0.001 \\
\hline sig. & $\mathrm{p}=0.000 * * *$ & $p=0.000 * * *$ & $p=0.000 * * *$ & $p=0.000 * * *$ & $\mathrm{p}=0.000 * * *$ & $\mathrm{p}=0.000^{* * *}$ \\
\hline \multicolumn{7}{|l|}{ Retail Space (sq. ft) } \\
\hline coeff. & 0.013 & 0.013 & 0.014 & 0.026 & 0.025 & 0.025 \\
\hline std. error & 0.003 & 0.003 & 0.003 & 0.003 & 0.003 & 0.003 \\
\hline sig. & $\mathrm{p}=0.000 * * *$ & $\mathrm{p}=0.000 * * *$ & $p=0.000 * * *$ & $p=0.000 * * *$ & $\mathrm{p}=0.000 * * *$ & $p=0.000 * * *$ \\
\hline \multicolumn{7}{|l|}{ Hotel Space (\# units) } \\
\hline coeff. & -0.001 & -0.001 & -0.001 & -0.003 & -0.003 & -0.003 \\
\hline std. error & 0.003 & 0.003 & 0.003 & 0.003 & 0.003 & 0.003 \\
\hline sig. & $p=0.763$ & $p=0.747$ & $p=0.771$ & $p=0.332$ & $p=0.321$ & $p=0.330$ \\
\hline \multicolumn{7}{|l|}{ Population Density } \\
\hline coeff. & --- & -0.001 & --- & --- & -0.002 & --- \\
\hline std. error & & 0.003 & & & 0.003 & \\
\hline sig. & & $p=0.738$ & & & $p=0.573$ & \\
\hline \multirow{2}{*}{\multicolumn{7}{|c|}{$\begin{array}{l}\% \text { Population in Block Group } \\
\text { within } 1 / 4 \text { mile of Transit }\end{array}$}} \\
\hline & & & & & & \\
\hline coeff. & --- & -0.270 & --- & --- & -0.234 & --- \\
\hline std. error & & 0.235 & & & 0.239 & \\
\hline sig. & & $p=0.252$ & & & $p=0.330$ & \\
\hline High-Rise Condo LUC 230 & & & -0.093 & --- & --- & 0.055 \\
\hline coeff. & --- & --- & 0.174 & & & 0.177 \\
\hline $\begin{array}{c}\text { std. error } \\
\text { slg. }\end{array}$ & & & $p=0.593$ & & & $p=0.756$ \\
\hline \multicolumn{7}{|l|}{ Constant } \\
\hline coeff. & 3.016 & 3.196 & 3.075 & 2.869 & 3.079 & 2.834 \\
\hline std. error & 0.169 & 0.278 & 0.203 & 0.172 & 0.283 & 0.206 \\
\hline sig. & $p=0.000 * * *$ & $p=0.000 * * *$ & $p=0.000 * * *$ & $p=0.000 * * *$ & $\mathrm{p}=0.000^{* * *}$ & $\mathrm{p}=0.000^{* * *}$ \\
\hline Observations & 50 & 50 & 50 & 50 & 50 & 50 \\
\hline Log Likelihood & -244.976 & -244.3 & -244.828 & -241.02 & -240.518 & -240.969 \\
\hline Theta & $4.039 * * *(0.865)$ & $4.146^{* * *}(0.890)$ & $4.063^{* * *}(0.871)$ & $3.943^{* * *}(0.839)$ & $4.029^{* * *}(0.859)$ & $3.953^{* * *}(0.841)$ \\
\hline LR (R0 vs. R1) & Chi $^{2}: 1.35$ (n.s.) & & & $\mathrm{Chi}^{2}: 1.004$ (n.s.) & & \\
\hline LR (R0 vs. R2) & $\mathrm{Chi}^{2}: 0.59$ (n.s. & & & $\mathrm{Chi}^{2}: 0.10$ (n.s.) & & \\
\hline RMSE & 99.10 & 108.00 & 96.80 & 230.00 & 232.00 & 231.50 \\
\hline NRMSE & 0.38 & 0.42 & 0.37 & 0.57 & 0.58 & 0.58 \\
\hline Akaike Inf. Crit. & 497.951 & 500.600 & 499.656 & 490.040 & 493.036 & 491.937 \\
\hline
\end{tabular}




\section{PERSON TRIP RATES - RESIDENTIAL-ONLY SITES}

Having assessed the findings for vehicle trip generation rates, we use the same analysis techniques for the person trip rates. As before, we segment this section into residential-only and mixed-use-only subsections.

Initially, we examine the differences in person trip rates across LUC using the KW test. Results are shown in Table 10. The results do not provide enough evidence to suggest significantly different person trip rates by LUC across PM peak hour data. However, the person trip rates from the AM peak show significant differences between high-rise apartments (LUC 222) and mid-rise apartments (LUC 223), and high-rise condominiums (LUC 232) and apartments (LUC 220). However, for land use codes 222, 223, and 232, the sample size for each is less than five observations and results are not conclusive. This may be an indication that the LUC may capture statistical differences in person trip rates, but it may also be an artifact of the low sample size.

Table 10. Kruskal-Wallis Tests Results (p-values) of the Variation of AM and PM Person Trip Rates Across Land Use Categories

AM Peak Hour

Mid-Rise Apt. High-Rise Apt. High-Rise Condo Apt. Condo Sample (223)

(222)

(232) (220) (230) Size (N)

\begin{tabular}{|c|c|c|c|c|c|c|}
\hline Mid-Rise Apt. (223) & --- & & & & & 24 \\
\hline High-Rise Apt. (222) & 0.01 & --- & & & & 4 \\
\hline High-Rise Condo (232) & 0.25 & 0.06 & --- & & & 2 \\
\hline Apt. (220) & 0.92 & 0.06 & 0.62 & --- & & 28 \\
\hline Condo (230) & 0.25 & 0.48 & 0.56 & 0.50 & --- & 3 \\
\hline \multicolumn{7}{|c|}{ PM Peak Hour } \\
\hline & $\begin{array}{r}\text { Mid-Rise } \\
\text { (223) }\end{array}$ & $\begin{array}{c}\text { h-Rise } \\
(222)\end{array}$ & $\begin{array}{l}\text {-Rise Condo } \\
\text { (232) }\end{array}$ & $\begin{array}{l}\text { Apt. } \\
\text { (220) }\end{array}$ & $\begin{array}{c}\text { Condo } \\
(230)\end{array}$ & $\begin{array}{c}\text { Sample } \\
\text { Size (N) }\end{array}$ \\
\hline Mid-Rise Apt. (223) & --- & & & & & 24 \\
\hline High-Rise Apt. (222) & 0.32 & --- & & & & 4 \\
\hline High-Rise Condo (232) & 0.77 & 0.35 & --- & & & 2 \\
\hline Apt. (220) & 0.40 & 0.78 & 0.41 & --- & & 28 \\
\hline Condo (230) & 0.54 & 1.00 & 0.56 & 0.71 & --- & 3 \\
\hline
\end{tabular}

Note: Bold values are significant at the 0.1 level 
As before, we estimate negative binomial regression models of person trip rates (for AM and PM peak separately) by development size (dwelling units), and either LUC or built environment measures. Similarly, we estimate three models for each peak period: $\left(R_{0}\right)$ base case with only site-specific site information; $\left(R_{1}\right)$ base case with built environment variables; and $\left(R_{2}\right)$ base case with land use codes. In this case, population density and the proportion of population in the area within 0.25 miles to transit were the two built environment variables with the highest level of significance. Results are shown in Table 11.

The results indicate significant improvements in model performance for $\mathrm{R}_{1}$ (development size and the built environment variables) over the base case model $R_{0}$ for the models for both the AM and PM peaks. There is not enough evidence to suggest a significant improvement for model $\mathrm{R}_{2}$, which includes the variables for the ITE land use codes. This finding is echoed when comparing RMSE and NRMSE which indicates that, for both AM and PM peak periods, the difference between predictions and observations is lowest for the contextual model $\left(R_{1}\right)$ compared with either the base case $\left(R_{0}\right)$ or the land use category $\left(R_{2}\right)$ model. This finding suggests using the built environment variables instead of ITE's land use categories gives a better prediction of person trip counts for residential-only multifamily housing in both the AM and PM peak periods.

For both peaks, the coefficients for population density and the proportion of population within 0.25 of transit were significant. The coefficient indicating proximity to transit had the largest effect size, suggesting a positive relationship between the proportion with close access to transit and higher person trip rates. For both time periods, the results suggest a small negative relationship between population density and person trip rates. The two variables are moderately and negatively correlated (Pearson's correlation of 0.38 ) in the estimated dataset. 
Table 11 Negative Binomial Regression Results for Person Trip Counts: (Ro) baseline, $\left(R_{1}\right)$ built environment, and $\left(R_{2}\right)$ land use categories (residential-only sites)

\begin{tabular}{|c|c|c|c|c|c|c|}
\hline \multirow{4}{*}{ No. of Dwelling Units } & \multicolumn{3}{|c|}{ AM PEAK } & \multicolumn{3}{|c|}{ PM PEAK } \\
\hline & \multirow[t]{2}{*}{$\mathrm{R}_{0}$} & \multirow[t]{2}{*}{$\mathrm{R}_{1}$} & \multirow[t]{2}{*}{$\mathrm{R}_{2}$} & \multirow[t]{2}{*}{$\mathrm{R}_{0}$} & \multirow[t]{2}{*}{$\mathrm{R}_{1}$} & \multirow[t]{2}{*}{$r_{2}$} \\
\hline & & & & & & \\
\hline & 0.005 & 0.004 & 0.004 & 0.004 & 0.004 & 0.004 \\
\hline std. error & 0.000 & 0.000 & 0.000 & 0.000 & 0.000 & 0.000 \\
\hline sig. & $\mathrm{p}=0.000 * * *$ & $\mathrm{p}=0.000 * * *$ & $\mathrm{p}=0.000^{* * *}$ & $\mathrm{p}=0.000 * * *$ & $\mathrm{p}=0.000 * * *$ & $p=0.000 * * *$ \\
\hline \multicolumn{7}{|l|}{ Population Density } \\
\hline coeff. & --- & -0.008 & --- & --- & -0.007 & --- \\
\hline std. error & & 0.003 & & & 0.003 & \\
\hline sig. & & $p=0.003 * * *$ & & & $\mathrm{p}=0.009 * * *$ & \\
\hline \multicolumn{7}{|c|}{$\begin{array}{l}\% \text { Population in Block Group } \\
\text { within } 1 / 4 \text { mile of Transit }\end{array}$} \\
\hline coeff. & --- & 0.426 & --- & --- & 0.316 & --- \\
\hline std. error & & 0.174 & & & 0.166 & \\
\hline sig. & & $p=0.015 * *$ & & & $p=0.058 *$ & \\
\hline \multicolumn{7}{|l|}{ High-Rise Apt. LUC 222} \\
\hline coeff. & --- & --- & 0.031 & --- & --- & 0.267 \\
\hline std. error & & & 0.244 & & & 0.224 \\
\hline sig. & & & $p=0.899$ & & & $p=0.234$ \\
\hline \multicolumn{7}{|l|}{ Mid-Rise Apt. LUC 223} \\
\hline coeff. & --- & --- & 0.300 & --- & --- & 0.326 \\
\hline std. error & & & 0.139 & & & 0.128 \\
\hline sig. & & & $p=0.031 * *$ & & & $\mathrm{p}=0.011 * *$ \\
\hline \multicolumn{7}{|l|}{ High-Rise Condo LUC 230} \\
\hline coeff. & --- & -- & 0.124 & --- & -- & 0.302 \\
\hline std. error & & & 0.278 & & & 0.255 \\
\hline sig. & & & $p=0.656$ & & & $p=0.237$ \\
\hline \multicolumn{7}{|l|}{ High-Rise Condo LUC 232} \\
\hline coeff. & & & 0.258 & & & 0.161 \\
\hline std. error & & & 0.332 & & & 0.307 \\
\hline sig. & & & $p=0.438$ & & & $p=0.600$ \\
\hline \multicolumn{7}{|l|}{ Constant } \\
\hline coeff. & 3.569 & 3.673 & 3.478 & 3.65 & 3.761 & 3.554 \\
\hline std. error & 0.099 & 0.143 & 0.103 & 0.093 & 0.136 & 0.095 \\
\hline sig. & $\mathrm{p}=0.000 * * *$ & $\mathrm{p}=0.000 * * *$ & $\mathrm{p}=0.000 * * *$ & $\mathrm{p}=0.000 * * *$ & $\mathrm{p}=0.000 * * *$ & $p=0.000 * * *$ \\
\hline Observations & 61 & 61 & 61 & 61 & 61 & 61 \\
\hline Log Likelihood & -310.388 & -305.109 & -307.619 & -309.585 & -305.624 & -306.021 \\
\hline Theta & $4.800^{* * *}(0.912)$ & $5.753^{* * *}(1.118)$ & $5.246 * * *(1.002)$ & $5.512^{* * *}(1.063$ & $6.339 * * *(1.247)$ & $6.217^{* * *}(1.214)$ \\
\hline LR (RO vs. R1) & \multicolumn{3}{|c|}{ Chi $^{2}: 10.6(p-$ value $<0.01)$} & \multicolumn{3}{|c|}{ Chi $^{2}: 7.9(p$-value $<0.05)$} \\
\hline LR (ROvs. R2) & $\mathrm{Chi}^{2}: 5.5$ (n.s.) & & & $C h i^{2}: 7.1$ (p-valt & $e<0.2)$ & \\
\hline RMSE & 196.40 & 118.80 & 191.00 & 169.30 & 110.00 & 144.10 \\
\hline NRMSE & 0.47 & 0.29 & 0.46 & 0.37 & 0.24 & 0.32 \\
\hline Akaike Inf. Crit. & 624.777 & 618.217 & 627.237 & 623.170 & 619.248 & 624.041 \\
\hline
\end{tabular}




\section{PERSON TRIP RATES - MIXED-USE SITES}

Lastly, we explore the relationship between person trip rates and either contextual variables or land use categories for mixed-use sites. Each set includes three models, similar to the residential-only sites: $\left(M_{0}\right)$ the base case with only site size variables; $\left(M_{1}\right)$ the base case with built environment indicators; and $\left(\mathrm{M}_{2}\right)$ the base case with LUC indicators. In this analysis, intersection density and the proportion of population within 0.25 miles of transit were the two highest performing built environment variables, although only intersection density was found to be marginally significant in either peak hour model. The addition of these variables did not make significant improvements according to the likelihood ratio tests (comparing $\mathrm{M}_{1}$ to $\mathrm{M}_{0}$ ). The addition of the ITE land use categories $\left(\mathrm{M}_{2}\right)$ did not perform much better in explaining person trip rates. While the performance of the built environment variables did not improve upon the AIC or the RMSE/NMSE values, the use of the land use categories did not improve model performance either. This indicates that the variables that contribute to activity at these mixed-use sites have still not yet been identified or tested in this analysis. 
Table 12 Negative Binomial Regression Results for Person Trip Counts: (Mo) baseline, $\left(M_{1}\right)$ built environment, and $\left(M_{2}\right)$ land use categories (mixed-use sites)

\begin{tabular}{|c|c|c|c|c|c|c|}
\hline & \multicolumn{3}{|c|}{ AM PEAK } & \multicolumn{3}{|c|}{ PM PEAK } \\
\hline & $M_{0}$ & $M_{1}$ & $\mathrm{M}_{2}$ & $\mathrm{M}_{0}$ & $\mathrm{M}_{1}$ & $\mathrm{M}_{2}$ \\
\hline \multicolumn{7}{|l|}{ No. of Dwelling Units } \\
\hline coeff. & 0.005 & 0.005 & 0.004 & 0.003 & 0.004 & 0.003 \\
\hline std. error & 0.001 & 0.001 & 0.001 & 0.001 & 0.001 & 0.001 \\
\hline sig. & $\mathrm{p}=0.000 * * *$ & $\mathrm{p}=0.000 * * *$ & $\mathrm{p}=0.000^{* * *}$ & $\mathrm{p}=0.000 * * *$ & $\mathrm{p}=0.000 * * *$ & $\mathrm{p}=0.002 * * *$ \\
\hline \multicolumn{7}{|l|}{ Retail Space (sq. ft) } \\
\hline coeff. & 0.010 & 0.009 & 0.010 & 0.018 & 0.017 & 0.019 \\
\hline std. error & 0.003 & 0.003 & 0.003 & 0.003 & 0.004 & 0.003 \\
\hline sig. & $\mathrm{p}=0.002 * * *$ & $\mathrm{p}=0.004^{* * *}$ & $\mathrm{p}=0.002 * * *$ & $\mathrm{p}=0.000 * * *$ & $\mathrm{p}=0.000 * * *$ & $p=0.000 * * *$ \\
\hline \multicolumn{7}{|l|}{ Hotel Space (\# units) } \\
\hline coeff. & 0.000 & 0.000 & 0.001 & 0.000 & 0.000 & 0.000 \\
\hline std. error & 0.003 & 0.003 & 0.003 & 0.003 & 0.003 & 0.003 \\
\hline sig. & $p=0.883$ & $p=0.882$ & $p=0.845$ & $p=0.999$ & $p=0.980$ & $p=0.994$ \\
\hline \multicolumn{7}{|l|}{ Intersection Density } \\
\hline coeff. & --- & -0.022 & --- & --- & -0.020 & --- \\
\hline std. error & & 0.015 & & & 0.017 & \\
\hline sig. & & $p=0.143$ & & & $p=0.234$ & \\
\hline \multirow{2}{*}{\multicolumn{7}{|c|}{$\begin{array}{l}\% \text { Population in Block Group } \\
\text { within } 1 / 4 \text { mile of Transit }\end{array}$}} \\
\hline & & & & & & \\
\hline coeff. & --- & -0.166 & --- & --- & -0.146 & --- \\
\hline std. error & & 0.216 & & & 0.240 & \\
\hline sig. & & $p=0.442$ & & & $p=0.543$ & \\
\hline \multicolumn{7}{|l|}{ High-Rise Condo LUC 230} \\
\hline coeff. & --- & --- & -0.255 & --- & --- & -0.233 \\
\hline std. error & & & 0.171 & & & 0.190 \\
\hline sig. & & & $p=0.137$ & & & $p=0.220$ \\
\hline \multicolumn{7}{|l|}{ Constant } \\
\hline coeff. & 4.331 & 4.451 & 4.493 & 4.795 & 4.885 & 4.93 \\
\hline std. error & 0.169 & 0.209 & 0.199 & 0.186 & 0.232 & 0.221 \\
\hline sig. & $\mathrm{p}=0.000 * * *$ & $p=0.000 * * *$ & $\mathrm{p}=0.000 * * *$ & $\mathrm{p}=0.000 * * *$ & $\mathrm{p}=0.000 * * *$ & $p=0.000 * * *$ \\
\hline Observations & 50 & 50 & 50 & 50 & 50 & 50 \\
\hline Log Likelihood & -309.541 & -308.347 & -308.457 & -330.781 & -329.959 & -330.016 \\
\hline Theta & $3.807^{* * *}(0.747)$ & $3.983^{* * *}(0.784)$ & $3.966 * * *(0.780)$ & $3.103^{* * *}(0.600)$ & $3.198^{* * *}(0.620)$ & $3.191 * * *(0.618)$ \\
\hline LR (R0 vs. R1) & $\mathrm{Chi}^{2}: 0.82$ (n.s.) & & & $\mathrm{Chi}^{2}: 1.18$ (n.s.) & & \\
\hline LR (R0 vs. R2) & Chi $^{2}: 2.16$ (p-value & $<0.2)$ & & Chi $^{2}: 1.52$ (n.s.) & & \\
\hline RMSE & 285.20 & 312.90 & 265.70 & 560.10 & 623.90 & 549.20 \\
\hline NRMSE & 0.29 & 0.32 & 0.27 & 0.43 & 0.48 & 0.42 \\
\hline Akaike Inf. Crit. & 627.083 & 628.694 & 626.915 & 669.561 & 671.918 & 670.032 \\
\hline
\end{tabular}




\section{Q3. CONVERTING VEHICLE TRIPS TO PERSON TRIPS}

In this last section, we address the performance of person trip rates that have been computed using the recommended ITE vehicle trip rate conversion approach. With too few observations of person trips in the archived ITE data compendium (or elsewhere), the recommended guidelines suggest converting the available vehicle trip data into estimates for person trips. The conversion of vehicle trips to person trips is made as follows, modified from the recommended guidelines (Institute of Transportation Engineers, 2014):

$$
P T_{\text {converted }}=\frac{V T_{I T E} * \text { VehOcc } c_{\text {Baseline }}}{\text { AutoMode } \text { Baseline }_{\text {Buting }}}
$$

$V T_{I T E}$ are the vehicle trip counts or rates obtained at standard ITE locations, or the "baseline" sites. Baseline sites are representative of typical locations collected and donated in conventional ITE studies - those sites tend to have little to no access to transit or bike facilities, with limited (if any) walkability, and free and unconstrained parking. In other words, ITE's recommendation for estimating person trip rates includes converting (very) suburban vehicle trip rates into person trip rates using estimates of vehicle occupancy and automobile mode share representative of these baseline locations. These person trip rates can then be applied to other environments, like the urban core or infill in transit-oriented neighborhoods, to estimate the overall person travel demand at various sites. The variables VehOcc $c_{\text {Baseline }}$ and AutoMode Baseline $_{\text {are }}$ are estimates of the typical average vehicle occupancy and automobile mode share to and from sites identified as baseline.

In some cases, these baseline mode share and vehicle occupancy rates are collected from actual sites by ITE and ITE's data donors. If this information is not provided, ITE recommends that the analyst assume some values that best represent what may have been observed in suburban, single-use contexts with free or unconstrained parking and little to no bicycling, walking, or transit use to and from the site (Institute of Transportation Engineers, 2014). For example, one previous application of ITE's adjustment approach assumed a universal $95 \%$ automobile mode share and 1.1 people per vehicle for all land uses where this information is not provided (Currans \& Clifton, 2015).

Once the person trip rates are approximated, the analyst can then apply this converted person trip rate to compute the vehicle trip rates for urban areas using the following formula, again modified from the recommended guidelines (Institute of Transportation Engineers, 2014):

$$
V T_{\text {context }}=\frac{P T_{\text {converted }} * \text { AutoMode } e_{\text {context }}}{V e h O c c_{\text {context }}}
$$


Where the vehicle trip estimates for the development context, $V T_{\text {context }}$, is estimated using an expected mode share and vehicle occupancy rate, AutoMode context $_{\text {and }}$ and VehOcc $c_{\text {context }}$, approximated for the development context (e.g., an urban neighborhood or district).These context-specific estimates can be approximated using external models like those estimated using intercept surveys (Institute of Transportation Engineers, 2014) or tools developed from household travel surveys (Currans \& Clifton, 2015; Ewing et al., 2011), or the user may rely on output from regional models or data provided by local agencies.

There are two issues that are problematic with this process. First, the analyst does not actually know the built environment or urban context from which most of the observed ITE or baseline data provided. Although ITE recommends only donating data collected from locations that meet these baseline conditions (e.g., unconstrained parking, no transit), the masking of location and context of provided data limits the analyst's ability to accurately make assumptions that reflect these baseline sites. In most cases, there is not enough information about any one site to know for sure which locations the data represents, and therefore, we do not address this assumption in this report.

Second, in applying this conversion approach, the analyst assumes the person trip rate calculated for suburban baseline contexts would reflect a similar person trip rate for the same land uses in urban contexts. In other words, the analyst assumes that the person trip rates at any land use observed in suburban locations are statistically similar to those observed in more urban locations. This leads to the question assessed in this section: how do person trip rates vary across built environment contexts?

To investigate this, we examined data from multiple studies collected for residential and lodging, offices, retail, and service land uses from multiple trip generation studies (District Department of Transportation, 2015; Clifton et al., 2015; Schneider et al., 2015; Texas A\&M Transportation Institute, 2017; Western District Institute of Transportation Engineers Chapter, 2017; Fehr \& Peers, 2015). These data were collected in built environments ranging from suburban to high-density urban locations, some with access to high-quality transit and some without. If ITE's "converted person trip" assumption holds, the converted person trip rates will not be statistically different across built environments and urban contexts and the distribution of difference between the converted estimates and observed rates (taken as a percentage of the estimated rates) should be normally distributed around zero.

To compare the accuracy of the estimated person rates, we compute the RMSE and the NRMSE between the converted estimate of trip rates and the observed trip rates, results are shown in Table 13. For each of the four land uses, these accuracy measures (RMSE and NRMSE) were computed for both AM and PM peak-hour rates (where available) ${ }^{6}$. A larger RMSE or NRMSE would indicate that there is a large difference between the predicted person trip rates and the observed rates.

\footnotetext{
${ }^{6}$ The peak-hour rates are defined as the maximum hour of person traffic at establishments during the peak hours of the adjacent street, most often defined between 7-9 a.m. and 4-6 p.m..
} 
Results show that the largest discrepancy between the predicted and actual person trip rates is in the retail and service land uses. This means that using ITE's conversion method to compute person trip rates for service and retail establishments is prone to errors, and it raises questions about the use of this method for these land uses. 
Table 13 Accuracy (RMSE and NRMSE) of ITE's Converted Person Trip Rates Compared with Observed

\begin{tabular}{lrrrrrr}
\hline & \multicolumn{3}{c}{ AM Peak Hour $^{5}$} & \multicolumn{3}{c}{ PM Peak Hour $^{5}$} \\
\cline { 2 - 7 } & \multicolumn{1}{c}{ RMSE } & NRMSE & Sample & \multicolumn{1}{c}{ RMSE } & NRMSE & Sample \\
\hline Residential/Lodging1 $^{1}$ & 0.098 & 0.068 & 58 & 0.078 & 0.054 & 58 \\
Office $^{2}$ & 0.233 & 0.186 & 24 & 0.335 & 0.173 & 23 \\
Service $^{3}$ & --- & --- & 0 & 2011.876 & 8.608 & 58 \\
Retail $^{4}$ & 229.184 & 7.376 & 15 & 579.407 & 4.731 & 60 \\
\hline
\end{tabular}

NOTES:

${ }^{1}$ ITE Land Use Codes: 220, 230, 222, 223, 232, 310

2ITE Land Use Codes: 710

3ITE Land Use Codes: 925, 932, 936

${ }^{4}$ ITE Land Use Codes: 850, 890, 880, 816, 851, 869, 820, 867, 530, 522

${ }^{5}$ The peak hour is measured during the peak of the adjacent street traffic, generally 7-9 a.m. and 4-6 p.m..

What these estimates do not show, however, is the direction of this error. A heavy bias in one direction or the other would mark a tendency to overestimate or underestimate person trip activity (and therefore multimodal behaviors).

To explore the over- and underestimation of person trip rates, we use the following metric:

Percent Difference of Observed to Estimated $=\frac{P T_{\text {observed }}-P T_{\text {estimated }}}{P T_{\text {estimated }}}$

This value was computed for each observation and plotted against the size of each establishment or development (see Figure 1 and Figure 2). Noticeably, the results show that these estimates for retail and service land uses are biased and tend to underpredict total person trip activity more than residential/lodging and office uses. While some retail and service estimates overpredict person trips for every observation, the majority severely underestimate person trips. Thus, it is likely that these locations in urban areas have a large number of trips made by non-automobile modes.

By converting ITE's vehicle trip rates using the standard baseline assumptions described previously, one ignores that the vast majority of these person trips are likely capturing walking trips to and from retail and services in more accessible areas. While the vehicle trip conversion method assumes all urban contexts produce similar rates as suburban contexts, theories of urban economics would suggest that businesses and residents pay a premium to occupy locations with higher accessibilities to opportunities (e.g., Alonso 1964, Mills 1969). This suggests, at least for businesses, that their decisions to locate in more urban areas with higher accessibility might correspond with an expectation of higher rates of foot traffic. As some agencies are beginning to require the evaluation of pedestrian facilities during development review (as well as cycling and transit) in the form of multimodal level-of-service measures or person delay, the underestimation of person trips ignores these kinds of trips which, in urban contexts, likely make up additional pedestrian trips leveraging the higher accessibility. 
(a)

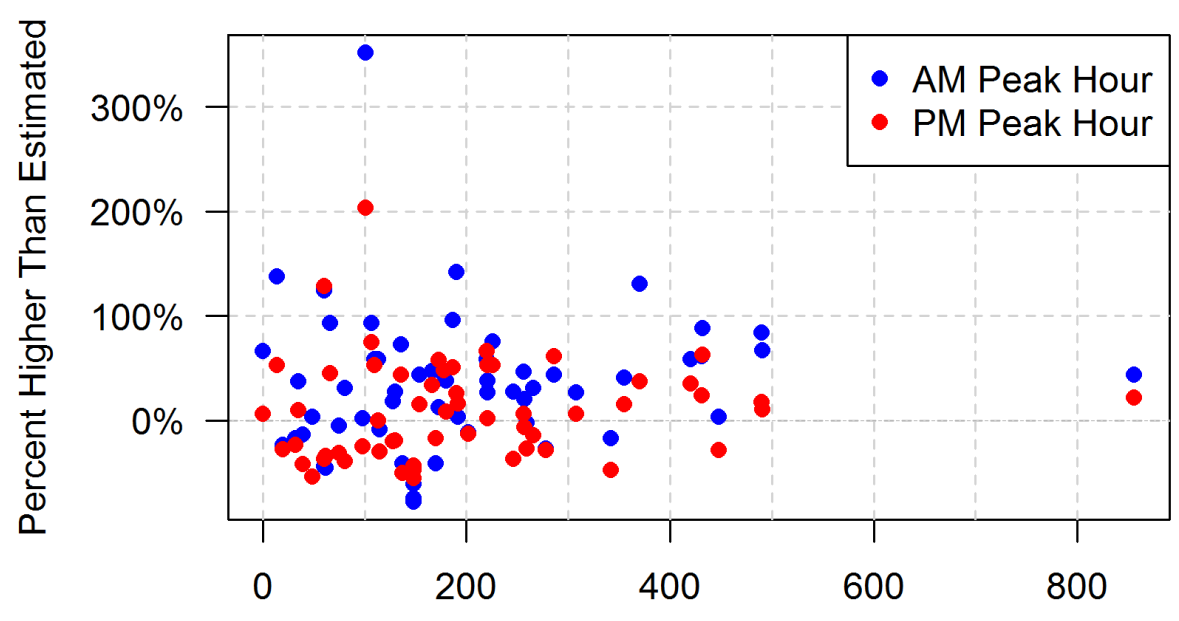

Occupied Dweling Units

(b)

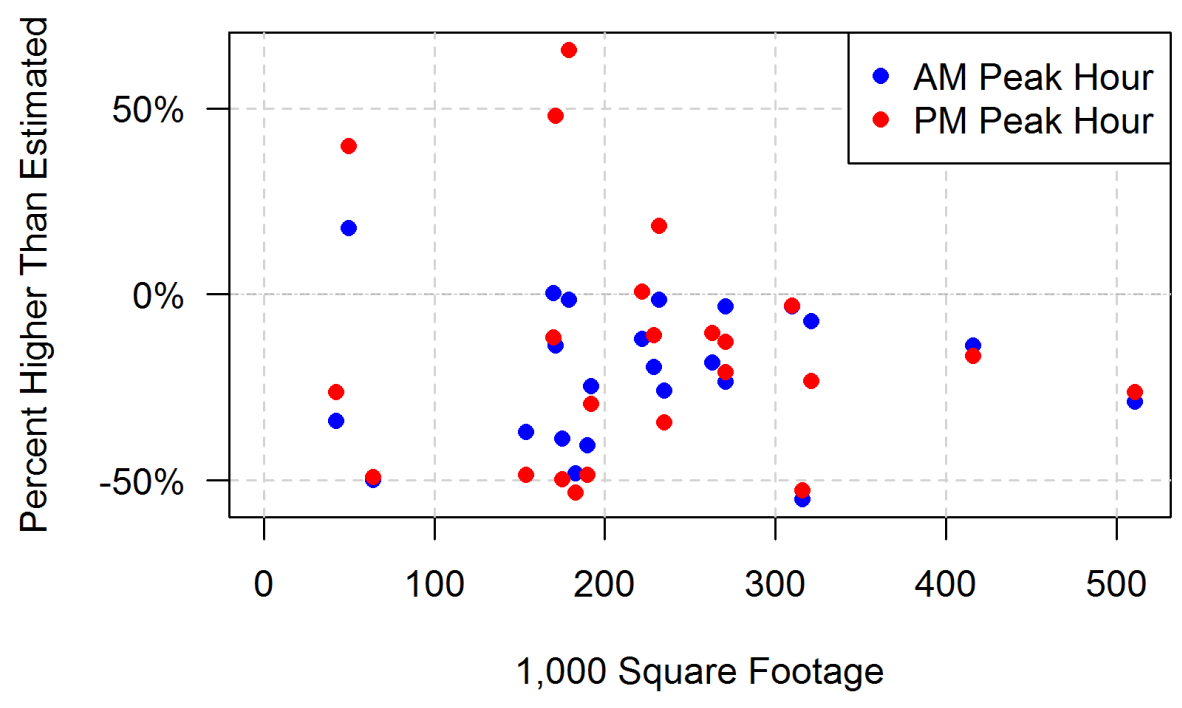

Figure 1 How Much Higher are the Observed Person Trip Rates Compared to Rates Estimated Using ITE's Converted Rates: (a) Residential and (b) Office 
(a)

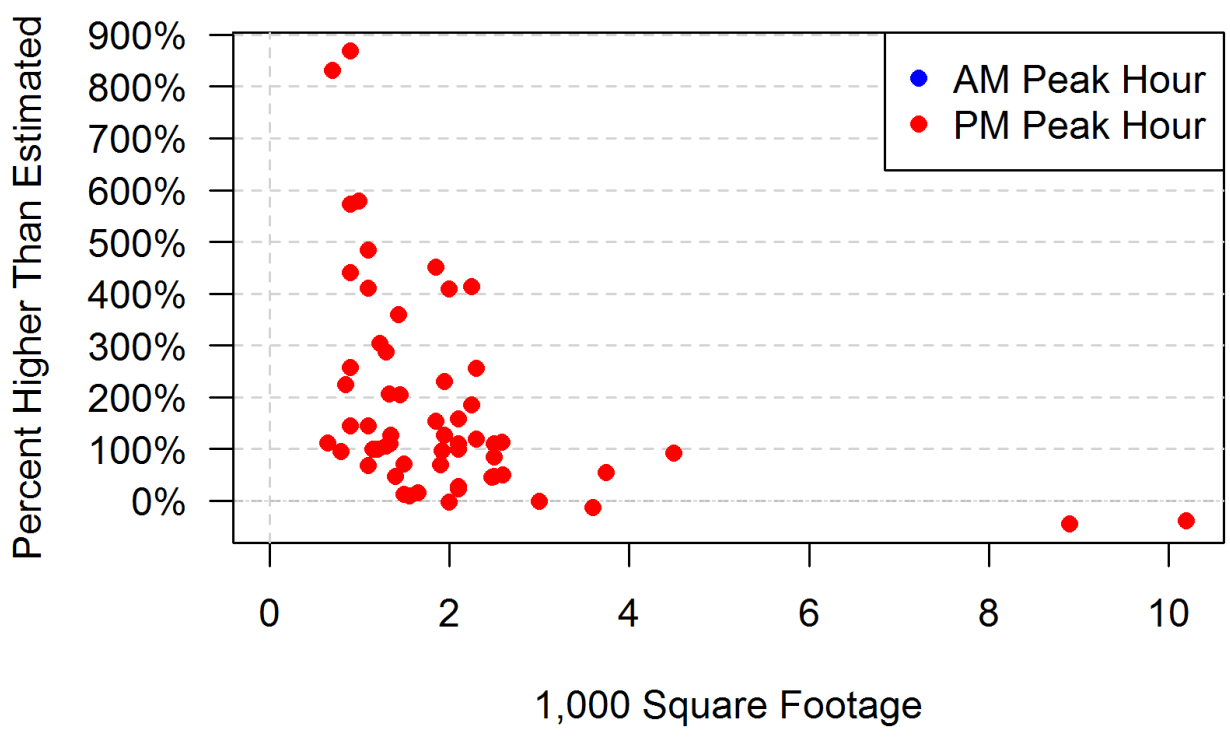

(b)

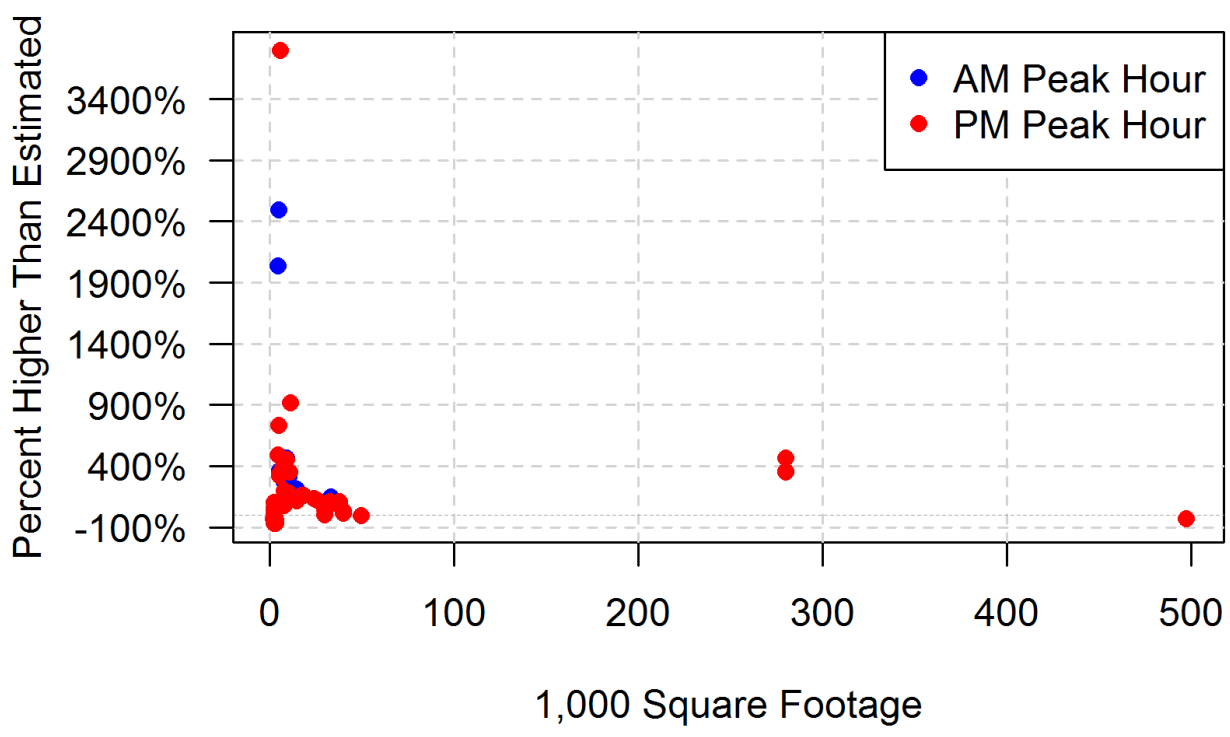

Figure 2 How Much Higher are the Observed Person Trip Rates Compared to Rates Estimated Using ITE's Converted Rates: (a) Service and (b) Retail 


\section{DISCUSSION AND CONCLUSIONS}

This project report has examined the advantages and limitations of the land use taxonomy for multifamily residential used in the ITE Trip Generation Handbook. with respect to their ability to act as a proxy for variations in the built environment. However, we find that the land use categories aiming to capture intensity of development for residential land uses (e.g., high-rise apartments) do not appear to capture any more variation in the vehicle or person trip rates when compared to measures of the built environment. For mixed-use sites, there was not enough information to capture a significant relationship between vehicle or person trip rates and a range of built environment variables that improves upon the variation captured from the developmentspecific variables (e.g., the number of dwelling units or square footage or retail space).

The recommended practice for converting ITE's vehicle trip rates into person trip estimations tends to severely underestimate person trip rates for retail and service land uses. This may suggest that the use of this approach, particularly in urban areas for retail and service uses, would ignore a potential larger number of non-automobile traffic to and from these commercial uses. While this approach fared better for residential and office uses, additional analyses that considers the relationship between over/underprediction and built environment metrics may help determine whether these prediction errors are biased across urban environment characteristics.

There are three main limitations in this analysis and the existing data: (a) existing studies used strategic sampling independently, often working to control for things like demographics; (b) lack of consistent data describing the sites; and (c) there exist limited individual-level information connecting the people who are being observed with the site (e.g., demographics).

In the first limitation, each study explored in this manuscript was independently designed and conducted in order to investigate specific research questions-most commonly pertaining to the relationship between vehicle trip counts and the built environment (e.g., activity density, intersection density, access to transit). Many of these studies explicitly control for locations with high or low income, leading to small levels of variation in demographic variables (and resulting in several non-significant findings in this study) in contradiction to what the academic travel behavior literature would suggest we would find.

In the second two limitations, little information about sites-and the residents inhabiting them-has been collected. Although many of these newer studies have gathered some of that information (distribution of dwelling unit sizes, parking availability or cost), few have gathered and implemented these data in a widely usable format.

Many cities are reconsidering their reliance on the ITE Trip Generation Handbook and rethinking what types of information are most helpful in evaluating transportation impacts. In this, a few things become clear. Person trip data are lacking, and an effort should be made to collect this information directly rather than use conversions from 
vehicle trip data. Person trips provide a better foundation to plan for multimodal travel and move away from a "predict and provide" perspective to one that is more proactive about transportation planning. The current taxonomy of land use codes does not offer needed flexibility as the character and passenger interaction with land uses changes over time. Land use codes that proxy for built environment or socioeconomic characteristics have limited usefulness over time and would best be replaced by actual information about the urban, demographic and economic context, such as density, mixed use, transit access, median incomes, or poverty rates. Finally, a more concerted effort to examine the usefulness of the various land use data presented in this data archive will be critical as transportation futures are headed for rapid change. With the introduction of transportation network companies, urban goods delivery and automated vehicles, vehicle trips may not have the same qualities as previous passenger trips in automobiles. 


\section{BIBLIOGRAPHY}

Alonso, W., 1964. Location and land use: Toward a general theory of land rent. ecological Bulletins.

Arup, 2015. Trip Genie: Context-sensitive trip generation rates. Available at: tripgenie.org. Accessed May 2017.

Blumenberg, E. \& Pierce, G., 2012. Automobile Ownership and Travel by the Poor: Evidence. Transportation Research Record: Journal of the Transportation Research Board, 2320(1), pp. 28-36.

Bochner, B. S., Hooper, K., Sperry, B. \& Dunphy, R., 2011. NCHRP Report 684: Enhancing Internal Capture Estimation for Mixed-Use Developments, Washington, D.C.: Transportation Research Board for the National Academies.

Clifton, K. J., Currans, K. M., Cutter, A. \& Schneider, R., 2012. Household Travel Surveys in a Context-Based Approach for Adjusting ITE Trip Generation Rates in Urban Contexts. Transportation Research Record: Journal of the Transportation Research Board, 2307(1), pp. 108-119.

Clifton, K. J., Currans, K. M. \& Muhs, C. D., 2013. Evolving the Institute of Transportation Engineers' Trip Generation Handbook: A Proposal for Collecting Multi-modal, Multi-context, Establishment-level Data. Transportation Research Record: Journal of the Transportation Research Board, Volume No. 2344 Travel Demand Forecasting, Vol. 2, pp. 107-117.

Clifton, K. J., Currans, K. M. \& Muhs, C. D., 2015. Adjusting ITE's Trip Generation Handbook for Urban Contexts. Journal of Transport and Land Use, 8(1), pp. 125.

Currans, K. M. \& Clifton, K. J., 2015. Improving Vehicle Trip Generation Estimation for Urban Contexts: Using Household Travel Surveys as a Method to Adjust ITE Trip Generation Rates. Journal of Tranpsort and Land Use, 8(1), pp. 1-35.

Daisa, J. M. et al., 2013. NCHRP Report 758: Trip Generation Rates for Transportation Impact Analyses of Infill Developments, Washington, D.C.: National Cooperative Highway Research Program.

District Department of Transportation, 2015. Trip Generation and Data Analysis Study, Washington, D.C.: District Department of Transportation.

Dock, S. et al., 2015. Methodology to Gather Multimodal Urban Trip Generation Data. Washington, D.C., National Academies of the Sciences, pp. 1-18.

Ewing, R. \& Cervero, R., 2010. Travel and the Build Environment: A Meta-Analysis. Journal of the American Planning Association, 76(3).

Ewing, R. et al., 2011. Traffic Generated by Mixed-Use Developments-Six-Region Study Using Consistent Built Environmental Measures. Journal of Urban Planning and Development, 137(3), pp. 248-261.

Fehr \& Peers, 2015. SF TDM Framework for Growth: Summary of Survey Results, San Francisco, CA: San Francisco Planning Department, San Francisco Municipal Transportation Agency.

Giuliano, G., 2005. Low Income, Public Transit, and Mobility. Transportation Research Record: Journal of the Transportation Research Board, 1927(1), pp. 63-70. 
Giuliano, G. \& Dargay, J., 2006. Car ownership, travel and land use: a comparison of the US and Great Britain. Transportation Research Part A, 40(1), pp. 106-124.

Institute of Transportation Engineers, 2012. Trip Generation Manual. 9th Edition ed. Washington, D.C.: Institute of Transportation Engineers.

Institute of Transportation Engineers, 2014. Trip Generation Handbook: An ITE Recommended Practice. 3rd edition ed. Washington, D.C.: Institute of Transportation Engineers.

Institute of Transportation Engineers, 2018. Trip Generation Manual. 10th edition ed. Washington, D.C.: Institute of Transportation Engineers.

Millard-Ball, A., 2015. Phantom Trips: Overestimating the traffic impacts of new development. Journal of Transport and Land Use, 8(1), pp. 1-19.

Mills, E. S., 1969. The Value of Urban Land. In: H. S. Perloff, ed. Quality of the Urban Environment, Resources for the Future. Washington, D.C.: s.n., pp. 231-253.

New York City, 2014. City Environmental Quality Review (CEQR): Chapter 16 Transportation, New York City: Mayor's Office of Environmental Coordination.

Pucher, J. \& Renne, J. L., 2003. Socioeconomics of Urban Travel: Evidence from the 2001 NHTS. Transportation Quarterly, 57(3), pp. 49-77.

San Francisco Planning Department, 2002. Transportation Impact Analysis Guidelines for Environmental Review, San Francisco, CA: City and County of San Francisco.

Schneider, R. J., Shafizadeh, K. \& Handy, S. L., 2015. Method to adjust Institute of Transportation Engineers vehicle trip-generation estimates in smart growth areas. Journal of Transport and Land Use, 8(1), pp. 69-83.

Schneider, R. J., Shafizadeh, K., Sperry, B. R. \& Handy, S. L., 2013. Methodology to Gather Multimodal Trip Generation Data in Smart-Growth Areas. Transportation Research Record: Journal of the Transportation Reserach Board, Volume 2354, pp. 68-85.

Shafizadeh, K. et al., 2012. Evaluation of Operation and Accuracy of Available Smart Growth Trip Generation Methodologies for Use in California. Transportation Research Record: Journal of the Transportation Research Board, 2307(1), pp. 120-131.

Tal, G. \& Handy, S., 2010. Travel behavior of immirants: An analysis of the 2001 National Household Transportation Survey. Transport Policy, 17(1), pp. 85-93.

Texas A\&M Transportation Institute, 2017. Trip Generation Rates for Transportation Impact Analyses of Smart Growth Land Use Projects, College Station, TX: The Texas A\&M University System.

Wang, L. \& Currans, K. M., 2018. Detransformation Bias in Nonlinear Trip Generation Models. Journal of Urban Planning and Development, 144(3), p. 04018021.

Weinberger, R., Ricks, K., Schrieber, J. \& Cohen, L., 2014. Trip Generation Data Collection in Urban Areas., Washington, D.C.: Research, Development \& Technology Transfer Program, Distric Department of Transportation, Federal Highway Administration.

Western District Institute of Transportation Engineers Chapter, 2017. "Data Collection Fund." Data Repository, s.I.: ITE Western District. 